\title{
Active integrins regulate white adipose tissue insulin sensitivity and brown fat thermogenesis
}

\author{
Francisco Javier Ruiz-0jeda ${ }^{1,2}$, Jiefu Wang ${ }^{1,2}$, Theresa Bäcker ${ }^{1,2}$, Martin Krueger $^{3}$, Samira Zamani ${ }^{1,2}$, \\ Simon Rosowski ${ }^{4}$, Tim Gruber ${ }^{2,5}$, Yasuhiro Onogi ${ }^{1,2}$, Annette Feuchtinger ${ }^{6}$, Tim J. Schulz ${ }^{2,7}$, \\ Reinhard Fässler $^{8}$, Timo D. Müller ${ }^{2,5,9}$, Cristina Garcia-Cáceres ${ }^{2,5}$, Matthias Meier ${ }^{4}$, Matthias Blüher ${ }^{2,10}$, \\ Siegfried Ussar ${ }^{1,2,11 \text {, }}$
}

\section{ABSTRACT}

Objective: Reorganization of the extracellular matrix is a prerequisite for healthy adipose tissue expansion, whereas fibrosis is a key feature of adipose dysfunction and inflammation. However, very little is known about the direct effects of impaired cell-matrix interaction in adipocyte function and insulin sensitivity. The objective of this study was to determine whether integrin activity can regulate insulin sensitivity in adipocytes and thereby systemic metabolism.

Methods: We characterized integrin activity in adipose tissue and its consequences on whole-body metabolism using adipose-selective deletion of $\beta 1$ integrin (ltgb1 ${ }^{\text {adipo-cre }}$ ) and Kindlin-2 (Kind2 ${ }^{\text {adipo-cre }}$ ) in mice.

Results: We demonstrate that integrin signaling regulates white adipocyte insulin action and systemic metabolism. Consequently, loss of adipose integrin activity, similar to loss of adipose insulin receptors, results in a lipodystrophy-like phenotype and systemic insulin resistance. However, brown adipose tissue of Kind2 ${ }^{\text {adipo-cre }}$ and Itgb $1^{\text {adipo-cre }}$ mice is chronically hyperactivated and has increased substrate delivery, reduced endothelial basement membrane thickness, and increased endothelial vesicular transport.

Conclusions: Thus, we establish integrin-extracellular matrix interactions as key regulators of white and brown adipose tissue function and whole-body metabolism.

\section{Keywords Integrins; Kindlin-2; Insulin resistance; Adipose tissue; Obesity; Brown fat; Insulin receptor; Lipodystrophy}

\section{INTRODUCTION}

Adipose tissue is essential to establish and maintain a functional metabolism [1]. A prerequisite for proper adipose tissue function during development and weight gain is its ability to grow through de novo adipogenesis (hyperplasia) or expansion of preexisting adipocytes (hypertrophy). Regardless of the mode of expansion, these processes require reorganization of the extracellular matrix (ECM) to provide ample space for the newly formed or enlarged adipocytes and to allow proper vascularization and innervation of the tissue. Thus, impaired adipose tissue expandability results in local hypoxia, tissue inflammation, insulin resistance, and adipocyte death [2-4]. These local pathologies, especially local insulin resistance, result in lipid spillover to organs, such as the liver and skeletal muscle, and the subsequent development of systemic insulin resistance and eventually development of the metabolic syndrome [5].

Various studies have investigated how changes in the ECM upon obesity and fibrotic ECM deposition contribute to increased tissue stiffness and the adipocyte dysfunction [6]. Moreover, several studies have investigated the role of individual ECM components in the development of obesity and the metabolic syndrome [7]. However, due to the complexity of and high redundancy in ECM proteins, thus far, these studies have failed to identify key ECM proteins promoting or inhibiting adipose tissue function [8]. Conversely, there are only a limited number of cell surface proteins regulating the organization of the ECM, and integrins are the best-studied cellular receptors performing these tasks [9]. Moreover, altered integrin signaling upon dietinduced obesity associates with insulin resistance [10-12]. Integrins

${ }^{1}$ RG Adipocytes and Metabolism, Institute for Diabetes and Obesity, Helmholtz Diabetes Center, Helmholtz Zentrum München, 85764 , Neuherberg, Germany ${ }^{2}$ German Center for Diabetes Research (DZD), 85764, Neuherberg, Germany ${ }^{3}$ Institute for Anatomy, University of Leipzig, 04103, Leipzig, Germany ${ }^{4}$ Microfluidic and Biological Engineering, Helmholtz Pioneer Campus, Helmholtz Zentrum Munich, 85764, Neuherberg, Germany ${ }^{5}$ Institute for Diabetes \& Obesity, Helmholtz Diabetes Center, Helmholtz Center Munich, 85764, Neuherberg, Germany ${ }^{6}$ Research Unit Analytical Pathology, Helmholtz Center Munich, 85764, Neuherberg, Germany ${ }^{7}$ German Institute of Human Nutrition Potsdam-Rehbrücke, Nuthetal, Germany ${ }^{8}$ Department of Molecular Medicine, Max Planck Institute of Biochemistry, Martinsried, Germany ${ }^{9}$ Department of Pharmacology, Experimental Therapy and Toxicology, Institute of Experimental and Clinical Pharmacology and Pharmacogenomics, Eberhard Karls University Hospitals and Clinics, Tübingen, Germany ${ }^{10} \mathrm{Helmholtz}$ Institute for Metabolic, Obesity and Vascular Research (HI-MAG) of the Helmholtz Zentrum München at the University of Leipzig and University Hospital Leipzig, Germany ${ }^{11}$ Department of Medicine, Technical University Munich, Munich, Germany

*Corresponding author. RG Adipocytes and Metabolism, Institute for Diabetes and Obesity, Helmholtz Diabetes Center, Helmholtz Center Munich, Ingolstaedter Landstrasse 1, 85764, Neuherberg, Germany. E-mail: siegfried.ussar@helmholtz-muenchen.de (S. Ussar). 
are a 24-member family of heterodimeric cell surface receptors composed of an $\alpha$ and a $\beta$ subunit, which are important to organize the ECM, facilitate anchorage of cells to the extracellular environment, and initiate diverse intracellular signaling [13]. Integrins reside at the cell surface in a bend low-affinity state and require inside-out activation to shift to a high-affinity confirmation enabling binding to ECM components. This activation process is facilitated by binding of intracellular adaptor proteins of the Talin and Kindlin families [14,15]. Kindlin-2, unlike the other two family members, is ubiquitously expressed [16] and essential for the activation of $\beta 1$-and $\beta 3$-containing integrins, when no other Kindlins are expressed [17-21]. The significance of Kindlin-2 in integrin activation is underscored by the peri-implantation lethality of Kindlin-2 knockout mice, which is very similar to the phenotype of $\beta 1$ integrin deficiency $[20,22]$. Importantly, however, Kindlins must cooperate with Talin to facilitate full integrin activation [23]. There are no knockout data on the role of Talins or integrins in adipose tissue, but recently the adipose-specific loss of Kindlin-2 was shown to cause age-associated lipodystrophy due to adipocyte apoptosis, resulting in insulin resistance and glucose intolerance [24]. Upon ECM binding, integrins initiate intracellular signaling through a process referred to as outside-in signaling, regulating key cellular functions, such as proliferation and survival [25]. Integrins lack kinase activity; thus, signaling is initiated through the recruitment of kinases to the $\beta$-integrin cytoplasmic tail, most prominently, the recruitment of focal adhesion kinase (FAK). FAK is a tyrosine kinase and important for the activation of multiple downstream signaling cascades, such as MAPK/Erk and PI3K/Akt [26]. Loss of FAK in adipose tissue results in a lipodystrophic phenotype with hepatosteatosis, insulin resistance, and glucose intolerance due to increased adipocyte apoptosis [27]. The similar phenotype between adipose-specific loss of Kindlin-2 and FAK further supports the central role of both proteins in integrin function. Furthermore, the overlapping downstream signaling of integrins and the insulin receptor suggest a potential effect of integrin signaling on insulin action. Indeed, previous work showed that $\alpha 5 \beta 1$ integrin activation enhances basal insulin receptor phosphorylation as well as insulin-stimulated insulin receptor substrate-1 (IRS-1) phosphorylation and recruitment of PI 3-kinase to IRS-1 [28]. Moreover, $\alpha \mathrm{v} \beta 3$ integrins and insulin signaling interact with each other [29,30]. However, the in vivo relevance of this interaction, as well as where in the signaling cascades these interactions occur, remain unknown. In contrast, previous work showed that $\beta 1$ integrins can directly interact with the IGF1R in skeletal muscle to regulate IGF-1 mediated skeletal muscle growth [31].

Thus, while several studies have investigated adipose tissue expansion and ECM remodeling and its metabolic consequences, the interaction between the ECM, integrins, and insulin action has not been studied in detail.

Here, we studied whether the ECM via integrins could regulate insulin sensitivity and thereby systemic metabolism, providing a potentially direct, inflammation-independent connection between insulin resistance and fibrosis. We show that $\beta 1$ and $\beta 3$ integrins are expressed in adipocytes, and their expression in subcutaneous and visceral fat correlates with obesity in mice and humans. Moreover, we describe a negative correlation of $\beta 1$ integrin expression in visceral adipose tissue with insulin sensitivity in men. To study the significance of the observed correlation, we characterize adipose-specific knockouts of $\beta 1$ integrin and Kindlin-2. Loss of $\beta 1$ integrin in adipocytes results in a moderate loss of adipose tissue mass with little consequences on whole-body insulin and glucose homeostasis and only a small reduction in FAK activity. In contrast, blunting $\beta 1$ and $\beta 3$ integrin activity through adipose selective inactivation of Kindlin-2 causes age- dependent loss in adipose tissue mass, adipose tissue fibrosis, and inflammation, as well as systemic insulin resistance. Mechanistically, we demonstrate that integrin signaling interacts with insulin signaling through multiple interactions of intracellular signaling nodes, including FAK, protein kinase B (AKT), and extracellular signal-related kinase (ERK) as well as receptor interactions to modulate white adipose tissue (WAT) function.

Surprisingly, although loss of Kindlin-2 causes systemic insulin resistance, especially when fed a high fat diet, we did not observe hepatic insulin resistance. We continue to demonstrate that this $\beta 1$ integrin-dependent atypical lipodystrophy phenotype is due to hyperactivated brown adipose tissue (BAT), resulting from increased substrate delivery through the endothelium to brown adipocytes.

\section{METHODS}

\subsection{Mice}

All mice were maintained in a conventional animal facility at a constant ambient temperature of $22 \pm 2{ }^{\circ} \mathrm{C}$, with $45-65 \%$ humidity and a 12-h light-dark cycle in ventilated racks. Cages and water were supplemented with nesting material and were changed every week. All mice received a standard chow diet (Altromin 1314, Lage Germany) and water ad libitum until further dietary interventions or death. Adiposeselective loss of $\beta 1$ integrin was generated by breeding $\operatorname{ltg} b 1^{\text {flox/flox }}$ mice (exons 2 to 7 of Itgb1 gene were flanked by LoxP sites) [32] with mice carrying Cre recombinase driven by the adiponectin promoter (Adipo-Cre) (Jackson Laboratories), both on a C57BL/6J background. $\mathrm{Itgb} 1^{\mathrm{fl} /+}$ heterozygous mice were bred to generate Adipo-Cre-positive littermate mice, and Adipo-Cre-positive males and Adipo-Cre-negative female mice were used for breeding. Male mice were used throughout the study, using Adipo-Cre-negative floxed $\left(\operatorname{ltgb} 1^{\mathrm{fl} / \mathrm{fl}}\right)$ as controls and the adipose-specific knockout Adipo-Cre-positive floxed (ltgb1 ${ }^{\text {adipo-cre }}$ ). Kindlin-2 (Fermt2) floxed mice were obtained by breeding Fermt2tm1a mice (EUCOMM)Wtsi (IMPC, GSF-EPD0087_1_G04-1) with Flp-deleter mice to remove the stop cassette and subsequently mating with C57BL/6J mice to remove the Flp transgene. Kind $2^{\text {flox/+ }}$ mice were intercrossed to obtain Kind $2^{\text {flox/flox }}$ mice. Adipose-selective loss of Kindlin-2 was generated by breeding Kind $2^{\text {flox/flox }}$ mice (exons 5 and 6 of Fermt2 gene were flanked by LoxP sites) with mice carrying Cre recombinase driven by the adiponectin promoter (Adipo-Cre) (Jackson Laboratories), both on a C57BL/6J background. Male and female mice were used, with Adipo-Cre-negative floxed (Kind $2^{\mathrm{fl} / \mathrm{fl}}$ ) as controls and the adipose-specific knockout Adipo-Cre-positive floxed (Kind2 ${ }^{\text {adipo- }}$ cre). A 58\% high-fat diet (HFD) was used for HFD feeding starting at 8 weeks old (Research Diets D12331, New Brunswick (NJ), USA) for a duration of 14 weeks. Body weight was determined at weekly intervals and body composition was measured by nuclear magnetic resonance measurements (EchoMRI ${ }^{R}$ LLC, Houston, USA) before the onset of the HFD feeding and prior to sacrificing the mice. For the thermoneutrality study, mice were housed at $30^{\circ} \mathrm{C}$. For cold exposure, mice were singly housed at $4{ }^{\circ} \mathrm{C}$ for 2 days for chronic cold exposure and $4{ }^{\circ} \mathrm{C}$ for $5 \mathrm{~h}$ for acute chronic cold exposure. Animal experiments were conducted in accordance with the German animal welfare law and performed with permission and in accordance with all relevant guidelines and regulations of the district government of Upper Bavaria (Bavaria, Germany), protocol number 55.2-1-54-2532-52-2016.

\subsection{Genotyping of mouse lines}

Eartags were obtained from mice at the age of 3 weeks, and DNA was isolated by boiling the eartags for $30 \mathrm{~min}$ in $100 \mu \mathrm{l}$ of $50 \mathrm{mM} \mathrm{NaOH}$ at $95{ }^{\circ} \mathrm{C}$ (ThermoMixer $\mathrm{C}$, Eppendorf). Afterward, $10 \mu \mathrm{l}$ of $1 \mathrm{M}$ Tris was 
added to normalize the $\mathrm{pH}$. One microliter of isolated genomic DNA was used for the genotyping polymerase chain reaction (PCR, Promega) using respective protocols.

\subsection{Energy metabolism studies}

Body composition (fat and lean mass) was analyzed using a magnetic resonance whole-body composition analyzer (EchoMRI, Houston, TX). Assessment of energy intake, water intake, respiratory exchange quotient (RER), and energy expenditure and home-cage activity were performed using an indirect calorimetry system (TSE PhenoMaster, TSE Systems, Bad Homburg, Germany). Following $24 \mathrm{~h}$ of acclimatization, $\mathrm{O}_{2}$ consumption and $\mathrm{CO}_{2}$ production were measured every $10 \mathrm{~min}$ for a total of $72 \mathrm{~h}$. Linear regression was used to analyze the energy expenditure, with body weight as covariate. Fecal caloric content was measured from dried fecal pellets collected from single cages using a 6300 0xygen Bomb Calorimeter (Parr Instrument Technology).

\subsection{Glucose and insulin tolerance tests (GTTs and ITTs)}

GTTs and ITTs were carried out in mice fasted for $4 \mathrm{~h}$. Two grams per kilogram of glucose (20\% Glucose solution; Braun) or $0.75 / 1.25 \mathrm{U}$ of insulin/kg BW (Actrapaid $\AA$ PenFill ${ }^{\circ}$ Novo Nordisk) were injected intraperitoneally (i.p.), and glucose concentrations were measured in blood collected from the tail before and 15, 30, 60, 90, and 120 min after the injection using a FreeStyle Freedom Lite glucometer (Abbott).

\subsection{Systemic insulin stimulation in vivo}

Mice were fasted for $4 \mathrm{~h}$, and recombinant human insulin $(100 \mathrm{IU} / \mathrm{ml}$, $50 \mu \mathrm{L}$; Humalin R) or saline was injected via the inferior vena cava after anesthesia with ketamine $(100 \mathrm{mg} / \mathrm{kg})$ and xylazine $(5 \mathrm{mg} / \mathrm{kg})$. The procedure was carried out under deep anesthesia and with the administration of metamizol $(200 \mathrm{mg} / \mathrm{kg})$ as an analgesic. During the experiment, mice were placed on a heating pad to prevent hypothermia. At 10 min after the injection, subcutaneous (SCF), perigonadal (PGF), BAT, and liver tissues were collected after decapitation.

\subsection{Serum, liver, and muscle metabolites}

Serum insulin levels were determined using the Mouse Ultrasensitive Insulin ELISA kit (Alpco). Serum free fatty acid (FFA) levels were measured with a Free Fatty Acids Quantification kit (BioVision), and serum leptin levels were determined using a Mouse/Rat Leptin Quantikine ELISA kit (R\&D systems). Liver and muscle triglyceride content were measured with the Triglyceride Quantification Colorimetric/Fluorometric kit (BioVision).

\subsection{Histology and imaging}

SCF, PGF, BAT, and liver were taken and fixed in 4\% paraformaldehyde (PFA, Carl Roth, Germany) at room temperature (RT) for $24 \mathrm{~h}$ dehydrated in an ascending row of ethanol (70-100\%) and xylene. Subsequently, tissues were embedded with paraffin (Leica, Germany) and cut into $2-\mu \mathrm{m}$ sections using a microtome (Leica, Germany). Dissected tissue sections were stained with hematoxylin and eosin (H\&E) as previously described [33] and Masson Trichrome staining. Quantification of lipid amount was morphometrically determined by automatic digital image analysis using the commercially available software Definiens Developer XD 2 (Definiens AG, Germany). Immunofluorescent staining was performed on paraffin sliced tissue sections, where antigen retrieval was achieved by boiling with citric acid $(\mathrm{pH}=6)$ for $10 \mathrm{~min}$ at $800 \mathrm{~W}$. After blocking with filtered 3\% bovine serum albumin/phosphate-buffered saline (BSA/PBS) at RT for $1 \mathrm{~h}$, slides were incubated with primary antibody (Fibronectin 1:50) at $4{ }^{\circ} \mathrm{C}$ overnight. After subsequent washing (3x PBS, RT, 5 min), the slides were incubated with the secondary antibody (anti rabbit 488 (1:200) and (DAPI, 1:5,000)), for $1 \mathrm{~h}$ at RT in the dark. Eventually, the slides were washed (3x PBS, RT, 5 min) mounted, cover-slipped, and dried for $1 \mathrm{~h}$. Imaging was performed with a Leica confocal SP5.

\subsection{Electron microscopy}

Animals were sacrificed and transcardially perfused with PBS followed by a fixative containing 4\% PFA (Serva, Heidelberg, Germany) and $1.5 \%$ glutaraldehyde (Serva). After dissection, the adipose tissue was post-fixed in the same fixative. Next, the fixed tissue was dissected into smaller blocks of approximately $1-2 \mathrm{~mm}^{3}$, which were then further fixed and stained with $0.5 \%$ osmium tetroxide (EMS, Hatfield, PA, USA) in PBS for 60 min and subsequently rinsed in PBS, followed by dehydration with $30 \%, 50 \%$, and $70 \%$ ethanol. Afterward, the tissue was stained with $1 \%$ uranyl acetate (Merck, Darmstadt, Germany) in $70 \%$ ethanol for $1 \mathrm{~h}$ and further dehydrated using $80 \%, 90 \%$, $96 \%$, and $100 \%$ ethanol and finally with propylene oxide (Sigma Aldrich, Steinheim, Germany). The samples were transferred in Durcupan (Sigma Aldrich) and embedded in gelatin capsules followed by the polymerization process at $56^{\circ} \mathrm{C}$ for $48 \mathrm{~h}$. After polymerization, the blocks of resin were trimmed and semi-thin sections were prepared using an ultra-microtome (Leica Microsystems, Wetzlar, Germany) to identify regions of interest at the level of light microscopy. After finally trimming the blocks of resin, ultra-thin sections were prepared at a thickness of $55 \mathrm{~nm}$. Sections were transferred on formvar-coated copper grids and stained with lead citrate. The analysis was performed using a Zeiss SIGMA electron microscope equipped with a STEM detector and ATLAS software (Zeiss NTS, Oberkochen, Germany).

For the analysis of basal lamina thickness per animal of each group, 19-21 vessels were analyzed. For each vessel, the basal lamina thickness was measured at 15 different measuring points to calculate the mean value per vessel and mouse. As sectioned vessels regularly exhibit parts with tangential sectioning, thereby artificially broadening the basal lamina, the analysis was confined to only the thinnest part of the basal lamina of each vessel. Endothelial vesicle density was addressed by counting endothelial vesicles in predefined sections of the vascular circumference to calculate the mean value of endothelial vesicles per $\mu \mathrm{m}$. Again, parts of the vascular circumference containing endothelial nuclei or accumulations of organelles as well as areas of tangential sectioning were excluded from the analysis.

\subsection{Cell culture}

To isolate primary cells, SCF from 8-week-old Kind2 $2^{\mathrm{fl} / \mathrm{fl}}$ and Kind2 $2^{\text {adipo- }}$

cre mice was excised and digested in $10 \mathrm{ml}$ of digestion mix (Dulbecco's modified Eagle's medium (DMEM) containing 1\% BSA and $0.1 \%$ collagenase IV) at $37^{\circ} \mathrm{C}$ and $1,000 \mathrm{rpm}$ shaking for $40 \mathrm{~min}$. For mature adipocyte isolation, digested SCF was filtered through a 250$\mu \mathrm{m}$ strainer and washed with $5 \mathrm{ml}$ of ice-cold PBS. The digested mix was left to stand for $15 \mathrm{~min}$ to allow adipocytes to float to the top. The layer of adipocytes was added to $1 \mathrm{ml}$ of Qiazol for subsequent RNA isolation. For isolation of primary preadipocytes, digested SCF and BAT was filtered through a $100-\mu \mathrm{m}$ filter and washed with $5 \mathrm{ml}$ of ice-cold PBS. The suspension was centrifuged at $800 \mathrm{~g}$ at RT for $5 \mathrm{~min}$. The supernatant was removed, and the pellet was re-suspended in $5 \mathrm{ml}$ of culture medium and centrifuged at $800 \mathrm{~g}$ at RT for $5 \mathrm{~min}$. The supernatant was discarded, and the pellet was re-suspended in $3 \mathrm{ml}$ of culture medium and eventually plated on a 6 -well plate. The cells were immortalized using an ecotropic SV40 large T retrovirus produced in HEK 293T cells. Differentiation of brown preadipocytes was induced by 
adding DMEM containing $10 \%$ fetal bovine serum (FBS), $1 \%$ penicillin and streptomycin, $500 \mu \mathrm{M}$ of IBMX/0.5NKOH, $5 \mu \mathrm{M}$ of dexamethasone/100\%ethanol, $125 \mu \mathrm{M}$ of indomethacin/dimethyl sulfoxide (DMS0), $100 \mathrm{nM}$ of insulin, and $1 \mathrm{nM}$ of T3 to each well (Day 0). After 2 days, the induction medium was replaced by freshly prepared differentiation medium (DMEM containing 10\% FBS, 1\% penicillin and streptomycin, $100 \mathrm{nM}$ of insulin, and $1 \mathrm{nM}$ of T3). This medium was changed every other day until the cells were fully differentiated (Day 8). Differentiation of white preadipocytes was induced by adding DMEM containing $10 \%$ FBS, $1 \%$ penicillin and streptomycin, $500 \mu \mathrm{M}$ of IBMX/ $0.5 \mathrm{NKOH}, 5 \mu \mathrm{M}$ of dexamethasone/ $100 \%$ ethanol, $125 \mu \mathrm{M}$ of indomethacin/DMSO, and $100 \mathrm{nM}$ of insulin to each well (Day 0). After 2 days, the induction medium was replaced by freshly prepared differentiation medium (DMEM containing 10\% FBS, 1\% penicillin and streptomycin, and $100 \mathrm{nM}$ of insulin). This medium was changed every other day until the cells were fully differentiated (Day 8).

\subsection{RNA isolation, reverse transcriptase (RT)-PCR, and real-time RT-PCR}

In liquid nitrogen, ground tissues of BAT $(20 \mathrm{mg})$, WAT $(80-100 \mathrm{mg})$, and liver $(20 \mathrm{mg}$ ) were homogenized in $1 \mathrm{ml}$ of Qiazol (Qiagen) using the TissueLyzer II from (Qiagen). Tissue homogenates were centrifuged $\left(4{ }^{\circ} \mathrm{C}, 2,500 \mathrm{~g}, 5 \mathrm{~min}\right.$ ), and the supernatant was added to $200 \mu \mathrm{l}$ of chloroform, vortexed, and centrifugated $\left(4^{\circ} \mathrm{C}, 18,400 \mathrm{~g}, 20 \mathrm{~min}\right)$. Three hundred fifty microliters of the RNA containing clear phase was further added to $70 \%$ ethanol, mixed well, and pipetted to a spin column of the RNeasy Mini Kit (Qiagen), and RNA isolation was further processed according to the manufacturer's instruction. RNA yield was determined using the Nanodrop (Nanodrop 2000, Thermo Fisher Scientific). For the determination of gene expression, cDNA synthesis $(0.5-1 \mu \mathrm{g}$ total RNA, High-Capacity cDNA Reverse Transcription Kit, Applied Biosystems) was performed according to the manufacturers' instructions. qPCR was performed in a CFX384 Touch (Bio- Rad), using $300 \mathrm{nM}$ of forward and reverse primers and iTaq Universal SYBR Green Supermix (Bio-Rad). The target gene expression was normalized on TATA box binding protein (TBP) expression. The primer sequences are shown in Extended Table S1. Differential expression levels were calculated via the $\Delta \Delta$ ct method [34].

\subsection{Protein extraction and western blot}

Tissues or cells were lysed with radioimmunoprecipitation assay (RIPA) buffer (50 mM of Tris pH 7.4, $150 \mathrm{mM}$ of $\mathrm{NaCl}, 1 \mathrm{mM}$ of EDTA, $1 \%$ Triton X-100), containing $0.1 \%$ sodium dodecyl sulfate (SDS), $0.01 \%$ protease-inhibitor, $0.01 \%$ phosphatase-inhibitor cocktail II, and $0.01 \%$ phosphatase-inhibitor cocktail III (all from Sigma). Samples were incubated on ice for $10 \mathrm{~min}$ and centrifuged for $10 \mathrm{~min}$ at $14.000 \times \mathrm{g}$ at $4{ }^{\circ} \mathrm{C}$. The supernatant was collected, and protein concentration was determined using the Pierce BCA protein assay kit (Thermo Fischer Scientific). Samples were mixed with $4 \mathrm{x}$ sample buffer (Life Technologies) containing 2.5\% $\beta$-mercaptoethanol (Carl Roth), boiled for $5 \mathrm{~min}$ at $95{ }^{\circ} \mathrm{C}$, loaded on $7.5-10 \%$ Tris gels for SDS-PAGE (polyacrylamide gel electrophoresis) with Fisher BioReagentsTM EZ-RunTM Prestained Rec Protein Ladder (ThermoFischer Scientific) as the molecular weight marker, and transferred to a polyvinylidene difluoride (PVDF) Immobilon-PSQ membrane, 0.45 microns (Merck Millipore). Unspecific binding sites were blocked with $5 \%$ non-skimmed milk in tris-buffered saline with Tween (TBS-T) and incubated in primary antibodies: FAK (Cell Signaling Technology D2R2E; 1:1,000), phosphoFAK (Tyr397) (Cell Signaling Technology D20B1; 1:1,000), Kindlin-2 (Cell Signaling Technology; 1:1,000), integrin beta 1 (Cell Signaling
Technology; 1:1,000), integrin beta 3 (Cell Signaling Technology; $1: 1,000$ ), cleaved caspase 3 (Cell Signaling Technology; 1:1,000), phosphor-p65-NFKB (Cell Signaling Technology; 1:1,000), NFKB (Cell Signaling Technology; 1:1,000), insulin receptor (Cell Signaling Technology; 1:1,000), phosphor-AKT (Ser473) and phosphor-AKT (Thr308), AKT (Cell Signaling Technology; 1:1,000), phosphor-ERK (Cell Signaling Technology; 1:1,000), ERK (Cell Signaling Technology; 1:1,000), phosphor-p70-S6K (Cell Signaling Technology; 1:1,000), p70-S6K (Cell Signaling Technology; 1:1,000), UCP1 (Cell Signaling Technology; 1:1,000), and $\alpha$-tubulin (Sigma; $1: 4,000$ ) at $4{ }^{\circ} \mathrm{C}$ overnight. After washing, secondary antibodies (anti-rabbit HRP (Cell Signaling Technology; 1:5,000)) and anti-mouse horseradish peroxidase (HRP, Cell Signaling Technology; 1:10,000) were incubated for $1 \mathrm{~h}$ at RT. The HRP-linked $\beta$-actin (Santa Cruz Biotechnology; 1:5,000) was incubated $1 \mathrm{~h}$ at RT. After washing, ECL (Merck Millipore) was added to the membranes, and the signal was detected using Bio-Rad ChemiDoc $^{\mathrm{TM}}$ Imagers (Bio-Rad) or with films (ECL high-performance chemiluminescence film (GE Healthcare Life Sciences) or CEA® RP New Medical X-Ray Screen Film Blue Sensitive (CEA Group). Quantifications were performed using ImageJ software.

\subsection{Co-immunoprecipitation assay}

Protein was extracted and lysed in NP-40 buffer [1\% NP-40, $20 \mathrm{mM}$ of Tris- $\mathrm{HCl}, \mathrm{pH} 7.5,150 \mathrm{mM}$ of $\mathrm{NaCl}, 1 \mathrm{Mm}$ of $\mathrm{CaCl}_{2}, 1 \mathrm{mM}$ of $\mathrm{MgCl}_{2}$, and $10 \%$ glycerol] containing $1 \%$ protease-inhibitor (Sigma-Aldrich) and then centrifuged for $30 \mathrm{~min}$ at $14,000 \mathrm{~g}, 4^{\circ} \mathrm{C}$. Cleared lysate was taken and protein concentration was determined by BCA assay. Four milligrams of total protein were incubated with $2 \mu \mathrm{g}$ of rabbit insulin receptor antibody (Cell Signaling Technology, \#3025) or $2 \mu \mathrm{g}$ of rabbit immunoglobulin G (IgG) control (Cell Signaling Technology, \#2729) for $4 \mathrm{~h}$ at $4{ }^{\circ} \mathrm{C}$ with rotation. Then, co-immunoprecipitated proteins were purified with $\mu$ columns (Miltenyi \#130-042-701) according to the manufacturer's protocol. In brief, $50 \mu$ of $\mu$ MACS Protein G MicroBeads (Miltenyi \#130-071-101) were added per approach and incubated for $1 \mathrm{~h}$ at $4{ }^{\circ} \mathrm{C}$ with rotation. All further steps were performed at $4{ }^{\circ} \mathrm{C}$. $\mu$ Columns were equilibrated with lysis buffer without glycerol (see above), and lysate was applied on columns. Columns were washed 4 times with lysis buffer without glycerol and 1 time with Dulbecco's phosphate-buffered saline (DPBS). Co-immunoprecipitated proteins were then eluted in $50 \mu$ of preheated $\left(95^{\circ} \mathrm{C}\right) 1 \mathrm{X}$ SDS sample buffer (NuPAGE LDS Sample Buffer, \#NP0008) supplemented with $2.5 \%$ 2-mercaptoethanol and analyzed by western blot. For SDS-gel electrophoresis, $4-12 \%$ gels (Thermo Fisher Scientific) were used and electrophoresis was performed at $200 \mathrm{~V}$ in MOPS Buffer for $45 \mathrm{~min}$. Blotting was performed in Tris $(25 \mathrm{mM})$, Glycin (192 mM) Buffer at $350 \mathrm{~mA}$ for $1.5 \mathrm{~h}$ on ice. For blocking, membranes were incubated for $1 \mathrm{~h}$ with $5 \%$ non-skimmed milk in TBS-T at RT. Membranes were incubated overnight with rabbit integrin beta 1 antibody (1:1,000, Cell Signaling Technology \#9699), rabbit integrin beta 3 (1:1,000, Cell Signaling Technology \#13166) and mouse IR antibody $\left(1: 1,000\right.$, Cell Signaling Technology \#3020S) in $5 \%$ BSA at $4{ }^{\circ} \mathrm{C}$. The next day, the membranes were washed 3 times with TBS-Tween 20 $0.1 \%$ for 5 min at RT. After washing, the membranes were incubated in secondary antibody, either anti-rabbit-IgG-HRP (1:5,000, Cell Signaling Technology \#7074) or anti-mouse IgG-HRP $(1: 5,000$, Santa Cruz Biotechnology \#2005) in 5\% milk TBS-Tween $200.1 \%$ for $1 \mathrm{~h}$ at RT. After 3 additional washing steps, each washed with TBS-Tween 20 $0.1 \%$ for $5 \mathrm{~min}$, ECL (Supersignal, West Dura, Thermo Fisher Scientific) was added to the membranes, and the signal was detected using BioRad ChemiDoc ${ }^{\mathrm{TM}}$ Imagers (Bio-Rad). 


\subsection{Proximity ligand assay (PLA)}

All incubation and wash steps were performed using a BioShake iQ at $500 \mathrm{rpm}$. For washing, $50 \mu \mathrm{l}$ of PBS were applied per well for $5 \mathrm{~min}$. In vitro differentiated subcutaneous white adipocytes were permeabilized in TBS-T buffer ( $0.05 \%$ Tween) for 10 min and blocked with $2 \%$ BSA in PBS for 30 min and washed twice with PBS, respectively. Primary antibodies were applied for $1 \mathrm{~h}$ at RT in antibody diluent (PLA kit, Sigma, DU092101). The following antibodies were used: anti-mouse insulin receptor (1:5, ThermoFisher CT-1), anti-rabbit integrin beta 1 (1:10, ThermoFisher, SA40-08), and anti-rabbit integrin beta 3 (1:40, ThermoFisher, SJ19-09). As a negative control, no primary antibody was used. The PLA assay was implemented as stated in the manufacturer's protocol, using the Duolink ${ }^{\mathrm{TM}}$ In Situ PLA $®$ ProbeAnti-Rabbit PLUS, Anti-Mouse MINUS and the In Situ Detection Reagents Orange (Sigma, DU092101). The staining solution had a final concentration of $25 \mu \mathrm{g} / \mathrm{ml} \mathrm{BSA}, 1 \mu \mathrm{g} / \mathrm{ml}$ of DAPI (Thermo), and Lipitox 488 (HCS LipidTOXTM Green Neutral Lipid Stain (1:200, InvitrogenTM, H34775) in $1 \mathrm{x}$ saline-sodium citrate buffer. Cells were washed 3 times, and imaging was performed with a Leica confocal SP5. Quantification was performed by counting the dots per nuclei of adipocytes.

\subsection{Glucose uptake assay}

For glucose uptake, murine WAT was dissected and digested for $30 \mathrm{~min}$ at $37^{\circ} \mathrm{C}$ in Krebs-Ringer buffer ( $20 \mathrm{mM}$ of sodium chloride, $5 \mathrm{mM}$ of potassium chloride, $2 \mathrm{mM}$ of calcium chloride, $1 \mathrm{mM}$ of magnesium chloride, $25 \mathrm{mM}$ of sodium bicarbonate, and $20 \mathrm{mM}$ HEPES) containing $1 \mathrm{mg} / \mathrm{ml}$ of collagenase type IV (Gibco) and $1 \%$ BSA (Albumin fraction V, Roth). The digestion was stopped by washing with PBS (Gibco) containing 1\% BSA, and it was left in repose for $20 \mathrm{~min}$ to allow the adipocytes to float. Adipocytes were incubated with or without insulin in the appropriate concentration $(1,10$, and $100 \mathrm{nM})$ for $20 \mathrm{~min}$ at $37^{\circ} \mathrm{C}$. Subsequently, adipocytes were incubated with 2deoxy-D-glucose (2-DOG) (Sigma) for $10 \mathrm{~min}$ at $37{ }^{\circ} \mathrm{C}$ (on ice for control) in the presence or absence of insulin. Glucose uptake was assayed in samples and normalized to protein concentration (Glucose Uptake Colorimetric kit, Sigma). Results are shown as 2-DG6P uptake in $\mathrm{pM}$ per $\mathrm{mg}$ of protein per min.

\subsection{Evans blue staining}

To obtain detailed information of the mouse BAT vascular profile, animals were anesthetized with a mixture of ketamine $(70 \mathrm{mg} / \mathrm{kg})$ and xylazine $(5 \mathrm{mg} / \mathrm{kg})$ transcardially perfused with $0.05 \%$ Evans blue (Sigma E2129) in $5 \mathrm{ml}$ of PBS (Gibco, pH 7.4). Perfusions were finalized with $20 \mathrm{ml}$ of $4 \%$ PFA in PBS, pH 7.4, and adipose tissues (SCF, PGF, and BAT) were removed and post-fixed in $4 \%$ PFA at $4{ }^{\circ} \mathrm{C}$. In either case, adipose tissues were then equilibrated with $30 \%$ sucrose in Tris-buffered saline (TBS, $\mathrm{pH} 7.2$ ) for $48 \mathrm{~h}$ before being sectioned into 30- $\mu \mathrm{m}$ coronal slices using a cryostat (CM3050S; Leica, Germany). Eventually, the slides were mounted, cover-slipped, and dried for $1 \mathrm{~h}$. Imaging was performed with optical microscope.

\subsection{Fluorescent angiography}

To obtain detailed information of the mouse BAT vascular profile, animals were sacrificed with $\mathrm{CO} 2$ and transcardially perfused with $20 \mathrm{ml}$ of PBS (Gibco, pH 7.4) supplemented with Lectin-FITC conjugate (25 $\mu \mathrm{g} / \mathrm{ml}$; Tritium vulgaris; L4895; Merck, Germany) using a peristaltic pump at $120 \mathrm{mmHG}$ (Instech, High Flow P720 equipped with $21 \mathrm{G}$ canula). Perfusions were finalized with $20 \mathrm{ml}$ of $4 \%$ paraformaldehyde (PFA) in PBS, pH 7.4, BAT was removed and post-fixed in $4 \%$ PFA at $4{ }^{\circ} \mathrm{C}$. In either case, adipose tissues were then equilibrated with $30 \%$ sucrose in Tris-buffered saline (TBS, pH 7.2) for $48 \mathrm{~h}$ before being sectioned into $30-\mu \mathrm{m}$ coronal slices using a cryostat (CM3050S; Leica, Germany). Eventually, the slides were mounted, cover-slipped, and dried for $1 \mathrm{~h}$. Imaging was performed with a Leica confocal SP5.

\subsection{Study in human subjects}

We included a cohort of 635 individuals from the Leipzig Biobank (432 women and $203 \mathrm{men}$ ) to represent a wide range of body mass index (BMl, 14.7-88.8 kg/m ${ }^{2}$ ) categories of lean (BMl $<25 \mathrm{~kg} / \mathrm{m}^{2}, \mathrm{n}=84$ ), overweight (BMl $25.1-29.9 \mathrm{~kg} / \mathrm{m}^{2}, \mathrm{n}=47$ ), or obesity (BMl $>30 \mathrm{~kg} /$ $\left.\mathrm{m}^{2}, \mathrm{n}=504\right)$. For Pearson's correlation between both $\beta 1$ and $\beta 3$ integrin gene expression in VAT and SAT and body fat percentage (\%), 123 individuals were selected for whom complete data sets were available (74 women and 49 men), categories of lean (BMl $<25 \mathrm{~kg} /$ $\left.\mathrm{m}^{2}, \mathrm{n}=24\right)$, overweight (BMI $25.1-29.9 \mathrm{~kg} / \mathrm{m}^{2}, \mathrm{n}=4$ ), and obese $\left(\mathrm{BMl}>30 \mathrm{~kg} / \mathrm{m}^{2}, \mathrm{n}=95\right)$. From those 123 individuals, 26 individuals had impaired fasting glycemia $(n=8)$, glucose tolerance $(n=14)$, or insulin resistance $(n=4)$. For correlation analyses between homeostasis model assessment of insulin resistance (HOMA-IR) and both $\beta 1$ and $\beta 3$ integrin gene expression, 115 individuals without type 2 diabetes with a HOMA-IR range between 0.02 and 13.3 were analyzed. Partial correlation, adjusted by body fat (\%) between both $\beta 1$ and $\beta 3$ integrins gene expression in VAT and SAT, and insulin resistance estimated from HOMA-IR was carried out in these individuals $(\mathrm{n}=115)$. Hypoxanthine phosphoribosyltransferase 1 (HPRT1) expression was used as reference gene. Collection of human biomaterial, serum analyses, and phenotyping were approved by the ethics committee of the University of Leipzig (approval numbers: 159-1221052012 and 017-12-23012012), and all individuals gave written informed consent before taking part in the study.

\subsection{Statistics}

All statistics were calculated using Microsoft Excel and GraphPad Prism 8. Data are presented as mean \pm standard error of the mean (SEM) unless stated differently in the figure legend. Statistical significance was determined by unpaired Student's t-test or, for multiple comparisons, using one- or two-way analysis of variance (ANOVA), followed by Tukey's multiple comparison's test, or as stated in the respective figure legend. Differences reached statistical significance with $p<0.05$. Correlations were established based on Pearson correlation tests for linear relationship with the variants. Correlation coefficient was provided, and the $p$-value and $r$ value were calculated. $p<0.05$ was considered as significant.

\section{RESULTS}

3.1. Expression of $\beta 1$ and $\beta 3$ integrins in adipose tissue positively correlates with body fat mass in humans

To study the relationship between body fat mass and systemic insulin sensitivity, we analyzed gene expression of $\beta 1$ and $\beta 3$ integrins in subcutaneous (SAT) and visceral adipose tissue (VAT) in 123 subjects with a range of BMls. We found a positive correlation between expression of $\beta 1$ integrin with body fat content in VAT and SAT in men and women, whereas $\beta 3$ integrin was positively correlated with body fat only in women (Figure 1A). Furthermore, expression of $\beta 1$ integrin in SAT, but not in VAT, positively correlated with insulin resistance, estimated by the HOMA-IR adjusted for body fat percentage in a subgroup of non-diabetic subjects $(n=115)$, in men but not in women (Fig. S1A). Next, we analyzed protein levels of both $\beta$ integrins, FAK, and Kindlin-2 in SCF and PGF adipose tissue of male mice fed either a chow (CD) or high-fat diet (HFD) for 14 weeks. Protein levels of $\beta 1$ 

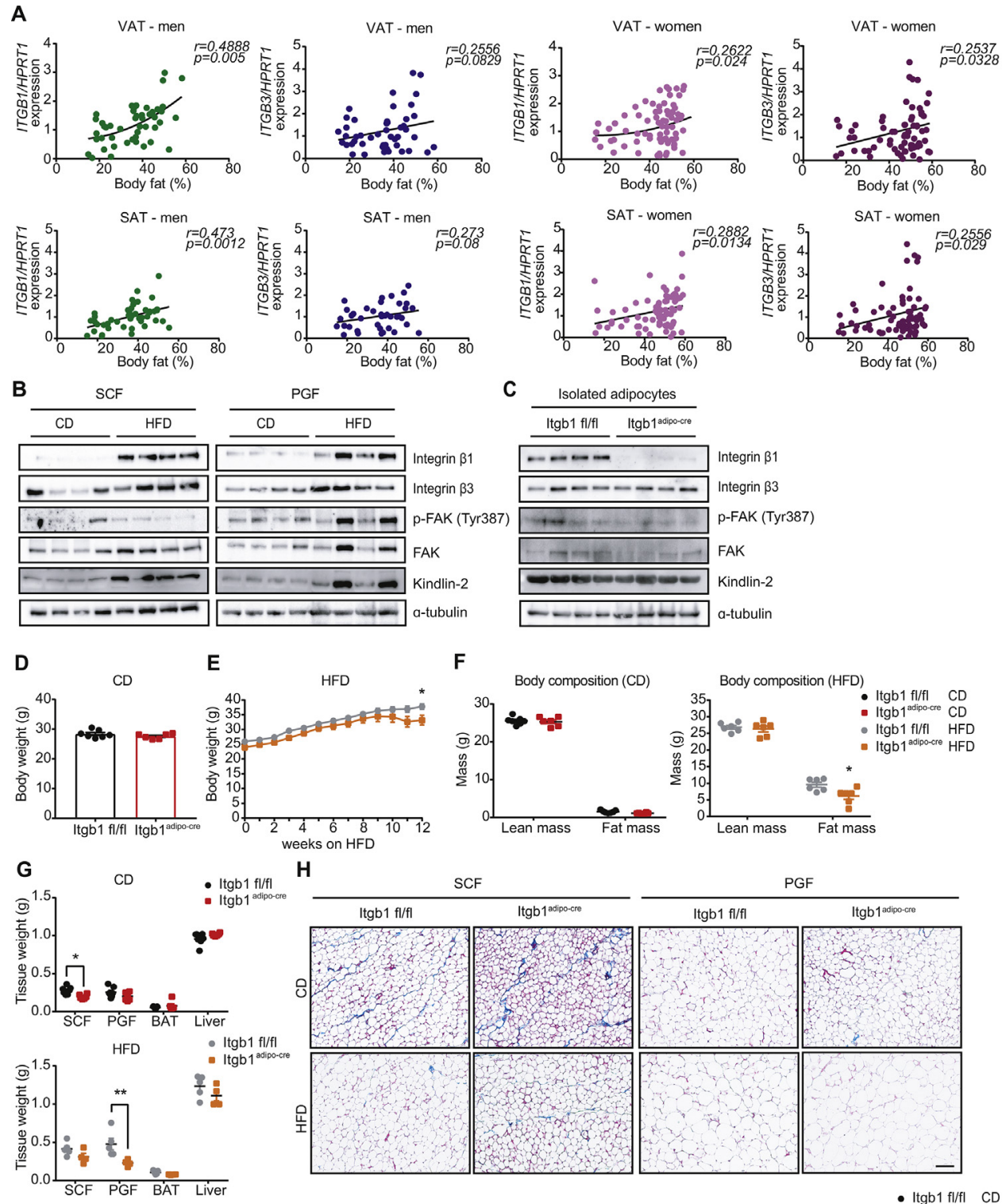

$\mathrm{H}$
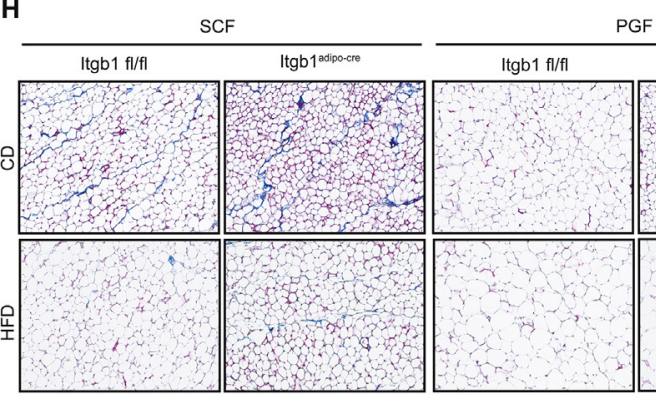
Itgb1 fl/fl $\quad \operatorname{ltg} 1$ 1alipo-cre
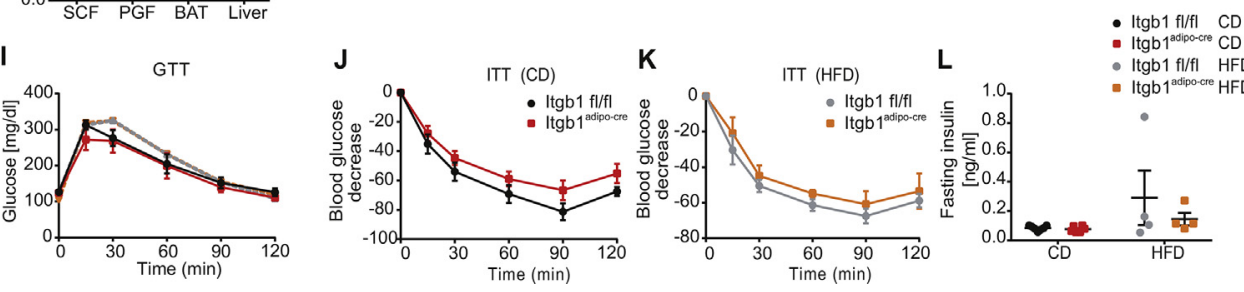

Figure 1: Expression of $\beta 1$ and $\beta 3$ integrins in adipose tissue are positively correlated with body fat mass in humans, and loss of $\beta 1$ integrin in adipose tissue moderately impairs HFD-induced obesity. (A) Pearson correlation between both beta 1 ( $\beta 1$ ) and beta 3 ( $\beta 3$ ) integrins in visceral (VAT) and subcutaneous (SAT) adipose tissue and body fat (\%) in subjects of a wide distribution of BMI $(\mathrm{n}=123,47$ men and 76 women). HPRT1 expression was used as reference gene. (B) Representative Western blot images for integrin $\beta 1$, integrin $\beta 3$, phospho(Tyr397)- and total FAK, Kindlin-2, and $\alpha$-tubulin in subcutaneous (SCF) and perigonadal adipose tissue (PGF) in both chow (CD)- and high-fat diet (HFD)-fed wild-type mice $(n=4)$. (C) Representative western blot images for integrin $\beta 1$, integrin $\beta 3$, phospho(Tyr397)- and total FAK, Kindlin-2, and $\beta$-actin in isolated adipocytes of SCF from integrin beta 1 flox mice (Itgb1 fl/fl) and Itgb1 flox; adiponectin-cre (ltgb1 ${ }^{\text {adipo-cre }}$ ) mice fed CD for 13 weeks $(n=4)$. (D) Body weight of Itgb1 fl/fl and Itgb $1^{\text {adipo-cre }}$ mice fed CD for 13 weeks $(n=7-6)$. (E) Body weight development of Itgb1 fl/fl and Itgb1 $1^{\text {adipo-cre }}$ mice fed HFD for 14 weeks $(n=6)$. (F) Body composition of Itgb1 fl/fl and Itgb1 ${ }^{\text {adipo-cre }}$ mice fed CD $(n=7-6)$ and HFD fed mice for 14 weeks $(n=6)$. (G) Tissue weights of SCF, PGF, brown adipose tissue (BAT), and liver of Itgb1 fl/fl and Itgb1 $1^{\text {adipo-cre }}$ mice fed CD $(n=7-6)$ and HFD for 14 weeks $(n=6)$. (H) Representative H\&E and Masson Trichrome staining of SCF and perigonadal adipose tissue (PGF) sections from Itgb1 fl/fl and Itgb1 $1^{\text {adipo-cre }}$ mice fed CD and HFD for 14 weeks (scale bar represents $100 \mu \mathrm{m}$ ). (I) Plasma glucose concentration during intraperitoneal glucose tolerance test $(2 \mathrm{~g} / \mathrm{kg})$ in Itgb1 fl/fl and ltgb1 adipo-cre mice fed CD $(n=7-6)$ and HFD for 14 weeks $(n=6)$. (J) Plasma glucose concentration during intraperitoneal insulin tolerance test $(0.75 \mathrm{IU} /$ $\mathrm{kg}$ ) in $\mathrm{Itgb} 1 \mathrm{fl} / \mathrm{fl}$ and $\mathrm{ltgb} 1^{\text {adipo-cre }}$ mice fed CD for 14 weeks $(\mathrm{n}=7-6)$. (K) Plasma glucose concentration during intraperitoneal insulin tolerance test $(1.25 \mathrm{lU} / \mathrm{kg})$ in Itgb1 fl/fl and $\mid \mathrm{Itgb} 1^{\text {adipo-cre }}$ mice fed HFD for 14 weeks $(\mathrm{n}=6)$. (L) Fasting insulin levels $(\mathrm{ng} / \mathrm{ml})$ in $\mid \mathrm{tgb} 1 \mathrm{fl} / \mathrm{fl}$ and $\operatorname{ltg} 1^{\text {adipo-cre }}$ mice fed $\mathrm{CD}(\mathrm{n}=7-6)$ and HFD for 14 weeks $(\mathrm{n}=6)$. Data are shown as mean $\pm \mathrm{SEM}$. Statistics were calculated using ordinary two-way ANOVA with Tukey's multiple comparison post-hoc test $\left(* * p<0.01,{ }^{*} \mathrm{p}<0.05\right)$. 
integrin were significantly increased in both SCF and PGF upon HFD feeding (Figure 1B and Fig. S1B). No statistically significant differences were observed in $\beta 3$ integrin levels. Kindlin-2 protein levels were increased in SCF but not statistically significant in PGF upon HFD feeding. p-FAK (Tyr387) and FAK were reduced in SCF but not in PGF upon HFD feeding (Figure 1B and Fig. S1B), which is in line with previous data on FAK [27]. Thus, integrins and integrin activity appear to be upregulated upon obesity in adipose tissues of mice and humans. However, it is important to note that $\beta 1$ and $\beta 3$ integrins are also expressed in non-adipocyte cells within adipose tissues, such as immune cells, which could contribute to the observed changes in tissue expression upon HFD feeding.

\subsection{Adipose-specific loss of $\beta 1$ integrin moderately impairs HFD induced weight gain}

$\beta 1$ integrin-containing integrins are the largest group of integrins binding to a diverse set of ECM components and thought to be the predominant integrins in adipocytes [25,35]. Moreover, correlation with body fat content in mice and humans was stronger for $\beta 1$ than $\beta 3$ integrins. Thus, to explore the role of integrins in adipose tissue, we generated a conditional knockout of $\beta 1$ integrin in adipose tissue by crossing $\beta 1$ integrin-floxed mice with adiponectin-cre C57BL/6J mice (Itgb $1^{\mathrm{fl} / \mathrm{fl}}$ are WT; and Itgb1 ${ }^{\text {adipo-cre }}$ are conditional knockout). $\beta 1$ integrin protein levels were reduced in total SCF lysates (Fig. S1C) and undetectable in isolated subcutaneous adipocytes (Figure 1C), confirming efficient deletion of $\beta 1$ integrin specifically in adipocytes. Loss of $\beta 1$ integrin did not alter body composition in 13-week-old CD fed mice (Figure 1D), but significantly reduced body weight after 8 weeks on HFD (Figure 1E), due to reduced fat and adipose tissue mass (Figure 1F,G). Adipose-selective depletion of Kindlin-2 and FAK, blunting integrin signaling, resulted in increased adipocyte death and Ioss of Kindlin-2 was reported to impair adipogenesis [24,27]. However, we did not observe differences in Pparg and adiponectin gene expression measured in primary subcutaneous adipocytes, indicating that adipogenesis per se is not impaired (Fig. S1D). Moreover, H\&E and Masson Trichrome staining did not indicate any abnormal ECM deposition or immune cell infiltrations in either SCF or PGF in CD and HFD fed mice (Figure $1 \mathrm{H}$ and Fig. S1E). Consequently, the slightly reduced fat mass did not affect glucose and insulin tolerance (Figure $1 \mathrm{I}-\mathrm{K}$ ), fasting insulin (Figure 1L), and glucose levels (Fig. S1F) upon either CD or HFD feeding. Taken together, adipocyte-specific loss of $\beta 1$ integrin did not significantly impair adipose tissue function and whole-body metabolism. However, loss of $\beta 1$ integrin also did not blunt overall integrin signaling as monitored by p-FAK (Figure $1 \mathrm{C}$ ), strongly suggesting compensation by other integrins, most likely $\beta 3$ integrins. To study the role of integrin activity in adipose tissue more generally, we generated adiposespecific loss of Kindlin-2, which regulates the activation of $\beta 1$ and $\beta 3$ integrins.

\subsection{Adipose-specific loss of Kindlin-2 blunts integrin activity, causing an age-dependent lipodystrophy-like phenotype}

We created a conditional knockout of Kindlin-2 in adipose tissue in C57BL/6J mice, breeding adiponectin-cre with Kind2 ${ }^{\mathrm{fl} / \mathrm{fl}}$ mice (Kind2 fl/ $\mathrm{fl}$ are WT; and Kind2 ${ }^{\text {adipo-cre }}$ are conditional KO). Kindlin-2 protein levels were strongly reduced in SCF, PGF, and BAT upon CD or HFD feeding (Figures 2A and S2A). Loss of Kindlin-2 completely blunted FAK (Tyr 397) phosphorylation (Figure 2A) and Rac1 activity (Figure 2B). Thus, loss of Kindlin-2 indeed inactivates all relevant integrins in adipocytes and p-FAK as well as Rac1 activity can be used to assess integrin activity in adipocytes. Unexpectedly, loss of Kindlin-2 also significantly reduced $\beta 1$ integrin protein levels but had no effect on $\beta 3$ integrins (Figure 2A).

Loss of Kindlin-2/integrin activity reduced adipose tissue mass at 10 weeks of age in CD fed mice (Fig. S2B) before changes in overall body weight were detected (Fig. S2C). Following 14 weeks of CD or HFD feeding, Kind $2^{\text {adipo-cre }}$ mice showed a significant decrease in fat mass and adipose tissue weights (Figure 2C,D), which translated to a decrease in overall body weight of HFD-fed mice (Fig. S2D and S2E). Consistent with the reduced fat mass, circulating leptin levels were markedly decreased in Kind2 ${ }^{\text {adipo-cre }}$ mice under HFD, but not in CD fed mice (Fig. S2F). However, FFA and triglyceride levels did not significantly differ in serum between groups (Fig. S2G-H). Importantly, we observed an identical phenotype in female Kind2 ${ }^{\text {adipo-cre }}$ mice with regard to body weight development (Fig. S2I), fat mass reduction (Fig. S2J), and the decrease in fat pad weights (Fig. S2K), resulting in an overall identical appearance upon HFD feeding (Fig. S2L). Thus, integrin inactivation in adipose tissue, mediated by loss of Kindlin-2, blunts HFD-induced obesity by reducing adipose tissue mass in an age-dependent manner, suggesting an impact on adipose tissue expansion.

In line with the reduced fat mass, we observed a reduction in adipocyte sizes in SCF and PGF (Figure 2E-F). We found increased fibronectin deposition in both SCF and PGF upon HFD feeding (Figure 2G), which was not observed for collagens using Masson's Trichrome staining (Figure 2E and Fig. S2M). In line with a lipodystrophic phenotype, loss of Kindlin-2 in adipose tissue increased inflammation and apoptosis upon HFD feeding (Figure $2 \mathrm{H}-\mathrm{I}$ ), as well as expression of senescence markers in isolated primary adipocytes (Fig. S2N). Moreover, phosphoHSL was reduced in PGF of Kind2 KO mice upon HFD feeding (Figure 2l). Kindlin-2-deficient primary subcutaneous adipocytes also showed increased Tnf- $\alpha$ expression, whereas expression of $1 / 1-\beta$, Pparg, C/Ebpo, or Fabp4 was not statistically different (Fig. S20). Normal Pparg, C/Ebp $\alpha$, or Fabp4 expression indicated that adipogenesis per se is not altered in adipocytes upon adiponectin-cre mediated deletion of Kindlin-2. We also did not observe differences in differentiation of primary brown adipocytes in vitro (Fig. S2P-Q). We observed a reduction in the expression of adiponectin and Pparg, but not in Fabp4, in Kindlin-2-deficient in vitro differentiated adipocytes from SCF at day 8. However, lipid accumulation, as investigated by brightfield imaging, was comparable between genotypes (Fig. S2R-S).

\subsection{Active integrins interact with insulin signaling to modulate insulin action}

The overall adipose tissue phenotype of Kind2 ${ }^{\text {adipo-cre }}$ mice showed many similarities to the adipose tissue knockout of the insulin receptor $[36,37]$. Furthermore, previous studies have suggested an interaction between integrin and insulin signaling [28]. Based on the data by Wang et al. [31], we tested the hypothesis that $\beta 1$ and $\beta 3$ integrins can directly interact and modulate insulin receptor function. Proximity ligation assays (PLA) indicated an interaction between $\beta 1$ and $\beta 3$ integrins with the insulin receptor in subcutaneous white adipocytes. Quantifications of the PLA experiments showed that the insulin receptor interaction with $\beta 1$ but not $\beta 3$ containing integrins was significantly reduced upon loss of Kindlin-2 (Figure 3A,B and Fig. S3A). A series of co-immunoprecipitation experiments also suggested a weak interaction between the insulin receptor and $\beta 1$ and $\beta 3$ integrins, which was reduced upon deletion of Kindlin-2 (Figure $3 \mathrm{C}$ ), and we observed a reduction in the insulin receptor protein levels in adipose tissues of Kindlin-2 knockout mice (Figure 3D). However, the overall interaction was very weak, with significant background remaining in the IgG controls. Thus, additional experiments are needed to confirm 
A

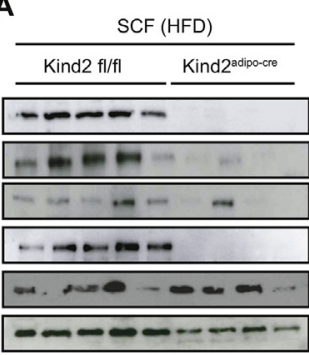

C

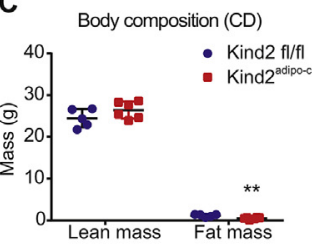

E

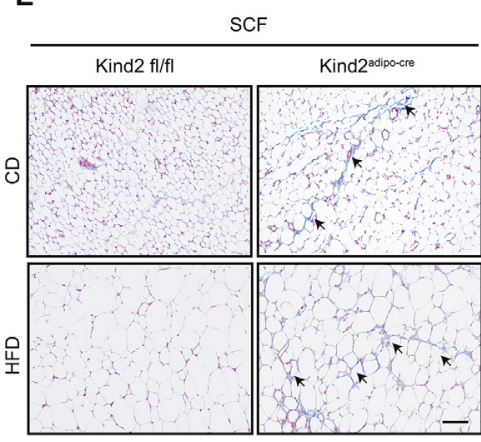

G

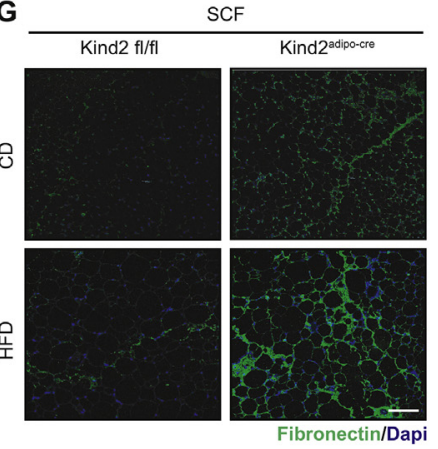

I

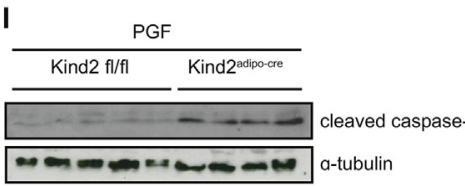

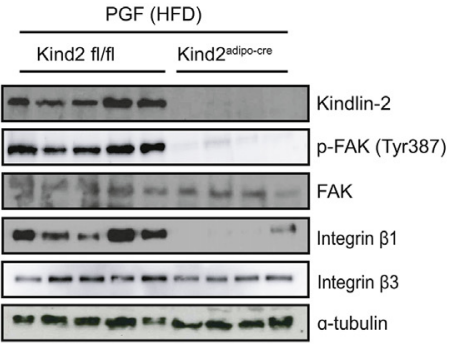

B

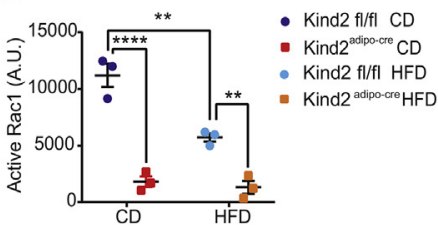

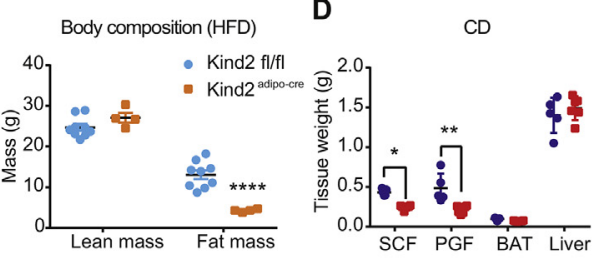

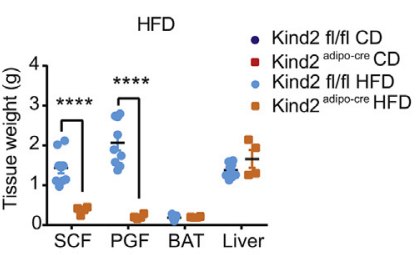

F
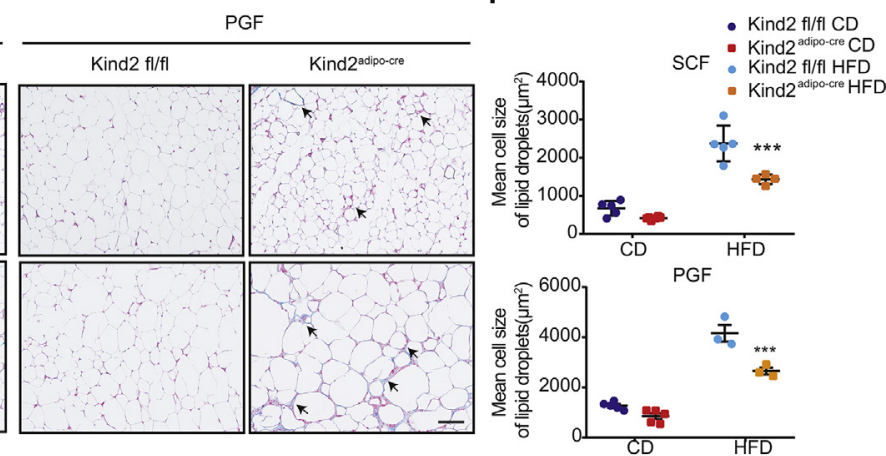

H

CD
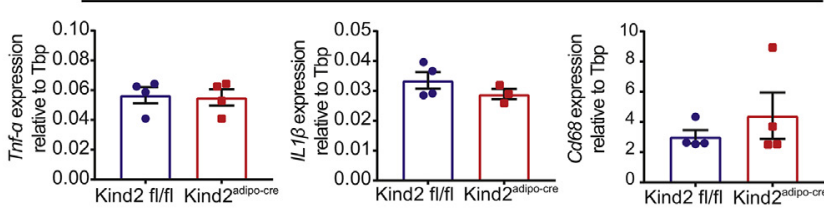

HFD
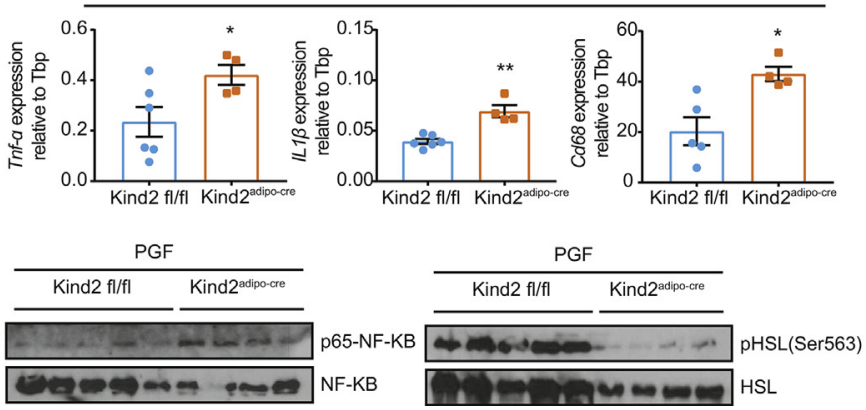

Figure 2: Adipose-specific loss of Kindlin-2 blunts integrin activity, causing age-dependent lipodystrophy. (A) Representative western blot images for Kindlin-2, phospho (Tyr397)- and total FAK, integrin beta 1 ( $\beta 1$ ), integrin beta 3 ( $\beta 3$ ) and $\alpha$-tubulin in subcutaneous adipose tissue (SCF), and perigonadal adipose tissue (PGF) from Kindlin-2 flox (Kind2 fl/fl) and Kindlin-2 flox; adiponectin-cre (Kind2 ${ }^{\text {adipo-cre }}$ ) mice fed HFD mice for 14 weeks. (B) Rac1 activation (small GTPases) in SCF of Kindlin-2 fl/fl and Kind2 ${ }^{\text {adipo-cre }}$ mice fed CD and HFD-fed mice for 14 weeks $(n=3)$. (C) Body composition of Kind2 fl/fl and Kind2 ${ }^{\text {adipo-cre }}$ mice fed $C D(n=5-6)$ or HFD for 14 weeks $(n=9-4)$. (D) Tissue weights of SCF, PGF, BAT, and liver of Kind2 fl/fl and Kind2 ${ }^{\text {adipo-cre }}$ mice fed $C D(n=5-6)$ or HFD for 14 weeks $(n=9-4)$. (E) Representative H\&E and Masson trichrome staining of SCF and PGF sections from Kind2 fl/fl and Kind2 ${ }^{\text {adipo-cre }}$ mice fed CD and HFD for 14 weeks. Arrow bars represent signs of inflammation (scale bar represents $100 \mu \mathrm{m}$ ). (F) Mean cell size quantification of lipid droplets $\left(\mu \mathrm{m}^{2}\right)$ in SCF and PGF from Kind2 fl/fl and Kind2 ${ }^{\text {adipo-cre }}$ mice fed $\mathrm{CD}(\mathrm{n}=5-5)$ and HFD for 14 weeks $(\mathrm{n}=5-4)$. (G) Immunofluorescence staining of fibronectin (green) and DAPI (blue) in SCF sections from Kind2 fl/fl and Kind2 adipo-cre mice fed CD and HFD for 14 weeks (scale bar represents $100 \mu \mathrm{m}$ ). (H) Relative gene

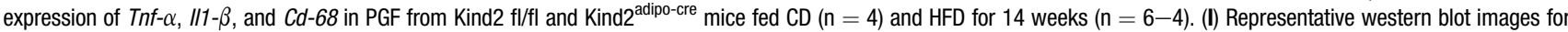
cleaved caspase-3 and $\alpha$-tubulin; phospho-(p65)-NF- $\mathrm{KB}$ and total NF- $\mathrm{KB}$ and for $\mathrm{p}-\mathrm{HSL}$ (Ser563) and HSL in PGF from Kind2 fl/fl and Kind2 ${ }^{\text {adipo-cre }}$ mice fed HFD for 14 weeks $(\mathrm{n}=5-4) . \alpha$-Tubulin is the same as that in panel A since there are the same blots and samples. Data are shown as mean \pm SEM. Statistics were calculated using two-way ANOVA with Tukey's multiple comparison post-hoc test $\left({ }^{* * *} \mathrm{p}<0.001,{ }^{* *} \mathrm{p}<0.01,{ }^{*} \mathrm{p}<0.05\right)$. 
A

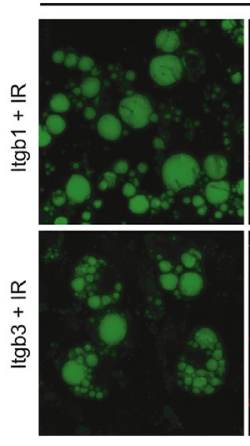

Kind2 fl/fl

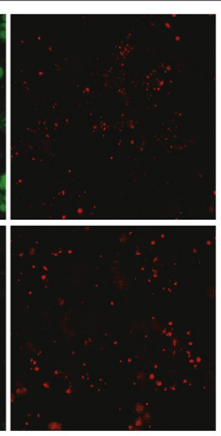

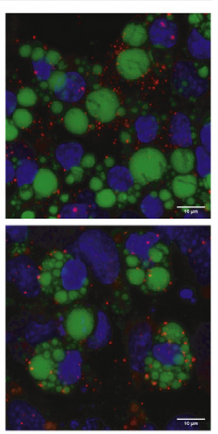

Itgb3 + IR

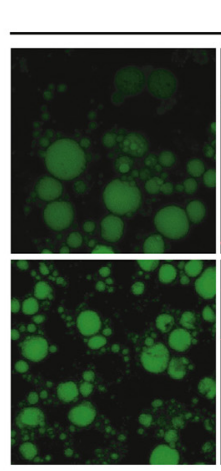

Kind2 $2^{\text {adipo-cre }}$

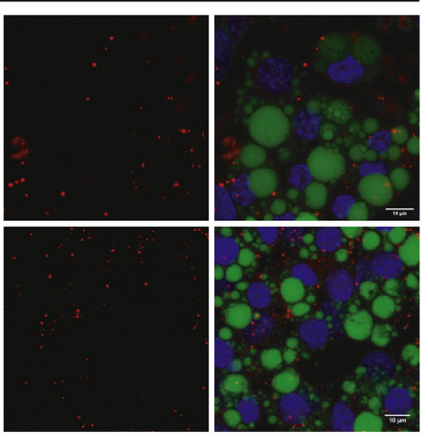

LIPIDTOX/PLA/DAPI

B

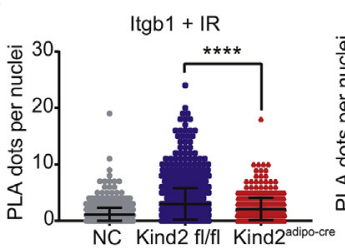

NC Kind2 fl/fl Kind2 2 adipo-cio

C

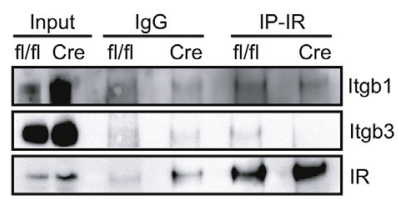

E

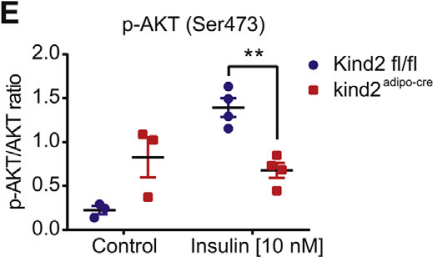

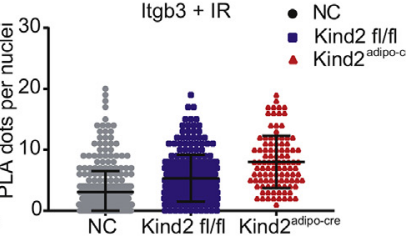

D

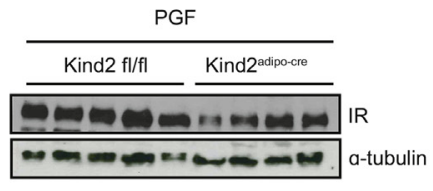

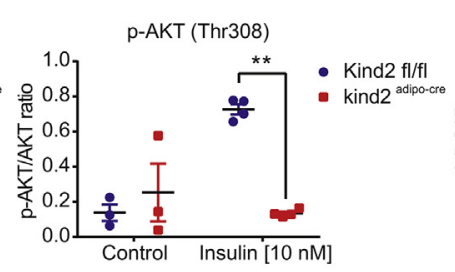

F

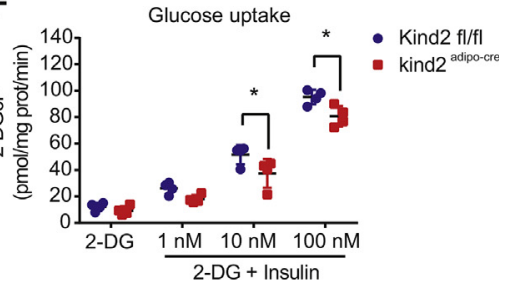

G
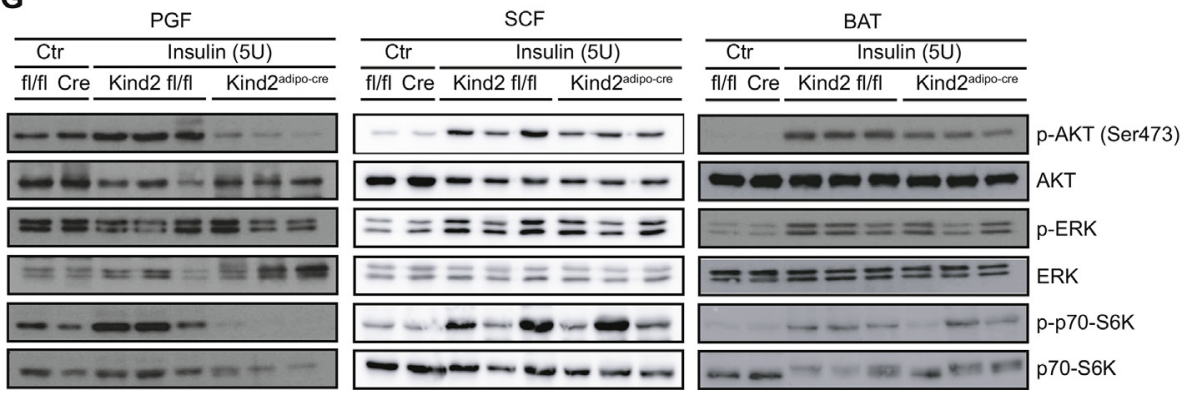

Figure 3: Active $\beta 1$ and $\beta 3$ integrins interact with the insulin receptor to modulate insulin action. (A) Immunofluorescence staining of lipid droplets (green), proximity ligand assay (PLA) (red) and 4',6-diamidino-2-phenylindole (DAPI) (blue) of immortalized preadipocytes from subcutaneous adipose tissue (SCF) of Kindlin-2 flox mice (Kind2 fl/fl) and Kind2 flox; adiponectin-cre (Kind2 ${ }^{\text {adipo-cre }}$ ) mice fed CD for 8 weeks, differentiated into adipocytes for 8 days. PLA between insulin receptor with both beta $1(\beta 1)$ and beta 3 ( $\beta 3$ ) integrins. (B) PLA quantification (dots per nuclei) of immortalized preadipocytes from subcutaneous adipose tissue (SCF) of Kind2 fl/fl and Kind2adipo-cre mice fed CD for 8 weeks, differentiated into adipocytes for 8 days. (C) Representative western blot for co-immunoprecipitation of insulin receptor together with both $\beta 1$ and $\beta 3$ integrins in perigonadal adipose tissue (PGF) from Kind2 fl/fl and Kind2 ${ }^{\text {adipo-cre }}$ mice fed CD for 8 weeks. More lysate from Kind2 ${ }^{\text {adipo-cre }}$ mice was used to compensate the reduction in $\beta 1$ integrin protein levels (see Figure 2A). (D) Representative western blot images for insulin receptor and $\alpha$-tubulin in PGF from Kind2 fl/fl and Kind2 ${ }^{\text {adipo-cre }}$ mice fed HFD for 14 weeks ( $\mathrm{n}=5-4$ ). The $\alpha$-tubulin is the same as that in panel A since there are the same blots and samples. (E) Western blot quantification for phospho-AKT (Ser473)/AKT and phospho-AKT (Thr308)/ AKT in primary adipocytes isolated from PGF of Kindlin-2 fl/fl and Kind2 ${ }^{\text {adipo-cre }}$ mice fed CD for 8 weeks in the presence or absence (control) of insulin [10 nM] for $10 \mathrm{~min}(\mathrm{n}=3$ ). (F) Ratio of glucose uptake (pmol/mg prot/min) in primary adipocytes isolated from PGF of Kindlin-2 fl/fl and Kind2 ${ }^{\text {adipo-cre }}$ mice fed CD for 8 weeks in the presence or absence of insulin [10 nM] for $10 \mathrm{~min}(\mathrm{n}=4) .2-\mathrm{DG}$ is 2-deoxyglucose. (G) Representative western blot images for phospho-AKT (Ser473), AKT, phospho-ERK, ERK, phospho-p70-S6K and S6K in PGF, SCF and brown adipose tissue (BAT) in the presence or absence (ctr = control, saline) of insulin from in vivo insulin stimulation in Kind2 fl/fl and Kind2 ${ }^{\text {adipo-cre }}$ mice fed HFD for 14 weeks $(n=3)$. Data are shown as mean \pm SEM. Statistics were calculated using two-way ANOVA with Tukey's multiple comparison post-hoc test $(* * p<0.01$, $* \mathrm{p}<0.05)$. 
an interaction between the insulin and integrin signaling at the receptor levels. However, insulin stimulation of primary perigonadal adipocytes from 8-week-old CD fed mice revealed strongly impaired Akt Ser473 and Thr308 phosphorylation (Figure 3E). We also confirmed a reduction in Akt phosphorylation at Ser473 in primary adipocytes from SCF (Fig. S3B). Furthermore, insulin-stimulated glucose uptake was significantly reduced (Figure $3 \mathrm{~F}$ ). Thus, these data demonstrated that active integrins interact with insulin signaling, and inactivation of integrins impairs insulin action. Adipose-selective knockout of mTORC1, through conditional ablation of raptor, resulted in a very similar lipodystrophic phenotype [38], also showing increased fecal caloric content upon HFD feeding as observed in the Kind $2^{\text {adipo-cre }}$ mice (Fig. S3C). In vivo insulin stimulation showed reduced Akt and p70-S6K phosphorylation in adipose tissue after 10 min in HFD fed Kind2 adipo-cre mice (Figure 3G). Akt phosphorylation was also reduced in BAT, although to a lesser extent than in WAT following intravenous insulin administration. However, we did not observe changes in phospho-p70S6K in BAT (Figure 3G).

\subsection{Loss of Kindlin-2 in adipose tissue causes systemic insulin} resistance without hepatosteatosis and hepatic insulin resistance Loss of Kindlin-2 in adipocytes resulted in an atypical lipodystrophic phenotype. Kind2 ${ }^{\text {adipo-cre }}$ mice developed insulin resistance upon 14 weeks of HFD feeding (Figure 4A-B). However, glucose tolerance was not impaired in Kind2 ${ }^{\text {adipo-cre }}$ mice (Figure 4 C) due to a compensatory increase in insulin secretion as evidenced by random fed hyperinsulinemia (Figure 4D). We also did not observe increased liver triglycerides (Figure $4 \mathrm{E}-\mathrm{G}$ ). The same phenotype was also observed when high-fat feeding was extended to 20 weeks (Fig. S4A-G). Moreover, ERK phosphorylation was higher in the liver of Kind2 ${ }^{\text {adipo-cre }}$ mice compared to controls when fed an HFD (Figure 4H). We also observed significantly lower Pepck expression in the liver (Figure 4I) and reduced fasting glycemia (Figure 4J) after 14 weeks on HFD feeding. All these data suggested increased hepatic insulin sensitivity. In vivo insulin stimulation confirmed increased Akt phosphorylation at Ser473 in the liver from Kind2 ${ }^{\text {adipo-cre }}$ mice compared to littermate controls (Figure 4K). Thus, loss of Kindlin-2/integrin activity in adipose tissue results in an atypical lipodystrophic phenotype with systemic insulin resistance that preserves liver insulin sensitivity.

\subsection{Loss of Kindlin-2 increases BAT activity independent from diet and housing temperature}

The absence of hepatosteatosis despite loss of adipose tissue mass suggested reduced food intake or increased energy expenditure. Assessment of food and water intake, as well as the respiratory exchange ratio, using metabolic cages, did not reveal any differences between control and Kind2 $2^{\text {adipo-cre }}$ mice fed either chow or HF diet (Fig. S5A-C). However, energy expenditure (EE) of Kind2 ${ }^{\text {adipo-cre }}$ mice was increased in HFD but not CD fed mice (Figure $5 A$ ), with a trend to higher UCP-1 protein levels upon HFD feeding (Figure 5B), and decreased lipid droplet size in Kind2 ${ }^{\text {adipo-cre }}$ mice fed either CD or HFD (Figure 5C-D). Moreover, fecal energy content of HFD-fed Kind2 $2^{\text {adipo- }}$ ${ }^{c r e}$ mice was significantly higher compared to controls, whereas we did not observe differences in CD-fed animals (Fig. S3C), phenocopying loss of raptor in adipose tissue [38]. Thus, a combination of increased brown fat activity together with elevated energy excretion through the feces appears to explain the absence of hepatosteatosis and hepatic insulin resistance in context of lipodystrophy of Kind $2^{\text {adipo-cre }}$ mice. To further characterize the effect of adipose tissue loss of Kindlin-2 on
BAT activity, HFD-fed Kind2 ${ }^{\text {adipo-cre }}$ and littermate control mice were housed at $4{ }^{\circ} \mathrm{C}$ for $48 \mathrm{~h}$ in metabolic cages. Kind2 adipo-cre mice showed increased EE (Figure 5E) and elevated food intake (Figure 5F) and RER (Figure $5 G$ ). In line with this, UCP1 protein (Fig. S5D), but not mRNA levels (Fig. S5E), were significantly increased in BAT of Kind2 ${ }^{\text {adipo-cre }}$ mice.

Cold exposure for $48 \mathrm{~h}$ induces the formation of brown-like adipocytes, called "beige" or "brite" (brown-in-white), within WAT depots [39]. However, we did not observe significant differences in Ucp1 and Prdm16 expression in SCF and BAT (Fig. S5E), albeit there was a clear trend for elevated Ucp1 expression in SCF of Kind2 ${ }^{\text {adipo-cre }}$ mice. We next tested whether inactivation of BAT in Kind $2^{\text {adipo-cre }}$ mice through a combination of HFD feeding and housing at thermoneutrality, as suggested previously by others [40-42], could result in hepatosteatosis and the development of metabolic complications classically associated with lipodystrophy. Housing HFD-fed Kind2 adipo-cre mice at $30{ }^{\circ} \mathrm{C}$ impaired diet-induced weight gain and accumulation of fat mass (Figure $5 \mathrm{H}, \mathrm{I})$ to a similar extent as mice housed at $\mathrm{RT}\left(23^{\circ} \mathrm{C}\right)$, while CD feeding did not result in body weight differences (Fig. S5F), but reduced fat mass (Figure 5l). Assessment of glucose and insulin tolerance, as well as fasting insulin levels largely confirmed the insulinresistant phenotype observed at RT (Figure 5J-K, Fig. S5G-H). However, unlike at RT, at thermoneutrality, HFD-fed Kind2 ${ }^{\text {adipo-cre }}$ mice showed increased fasting glycemia (Figure $5 \mathrm{~L}$ ), similar ERK activation (Fig. S5I), and Pepck gene expression in liver (Fig. S5J) when compared with littermate controls. Thus, while not affecting the phenotype in WAT, housing at thermoneutrality resulted in increased hepatic insulin resistance of Kind2 ${ }^{\text {adipo-cre }}$ mice compared to Kind2 ${ }^{\text {a- }}$ dipo-cre mice housed at RT. Nevertheless, also at thermoneutrality we did not observe ectopic lipid accumulation in liver (Figure $5 \mathrm{M}-\mathrm{N}$ ) or skeletal muscle (Fig. S5K). Consistently, we observed increased energy expenditure in Kind2 ${ }^{\text {adipo-cre }} \mathrm{HFD}$ fed mice housed at $30^{\circ} \mathrm{C}$ (Figure 50 ), a trend to increased UCP1 protein levels and decreased BAT lipid droplet size in both CD- and HFD-fed mice (Figure 5P-Q). Similar to mice housed at RT, food intake (Fig. S5L) and RER (Fig. S5M) were comparable to control mice.

Hence, Kind $2^{\text {adipo-cre }}$ mice displayed a previously undescribed hyperactive brown fat even upon thermoneutrality and HFD feeding, a situation with low sympathetic activity.

\subsection{Loss of $\beta 1$ integrin activity in brown adipocytes increases vascular permeability in BAT}

BAT is highly vascularized, with every brown adipocyte in contact with capillaries, only separated by a basement membrane [43]. Thus, changes in the vascularization or vascular permeability could deliver more substrate to brown adipocytes driving thermogenesis through substrate excess rather than sympathetic control. Indeed, intravenous perfusion with Evan's blue showed increased dye penetration into BAT of Kind2 ${ }^{\text {adipo-cre }}$ and Itgb1 $1^{\text {adipo-cre }}$ mice (Figure $6 \mathrm{~A}-\mathrm{B}$ ), indicative of increased vascular permeability. A similar phenotype was also observed in SCF and PGF (Fig. S6A-S6B). However, blood vessel density and morphology appeared normal in BAT of Kindlin-2 knockout mice (Fig. S6C). Electron microscopy (EM) revealed that loss Kindlin-2 and $\beta 1$ integrin reduced basement membrane thickness between the endothelium and brown adipocytes (Figures 6C-D and S6E) and increased endothelial vesicle density (Figures 6E and S6F), whereas endothelial overlap was unaltered (Fig. S6D), indicating increased trans-endothelial transport to brown adipocytes. Importantly, we observed a similar increase in Evan's blue penetration in BAT of $\beta 1$ 


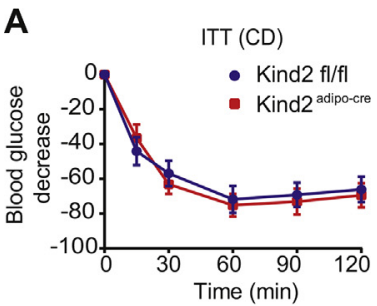

E

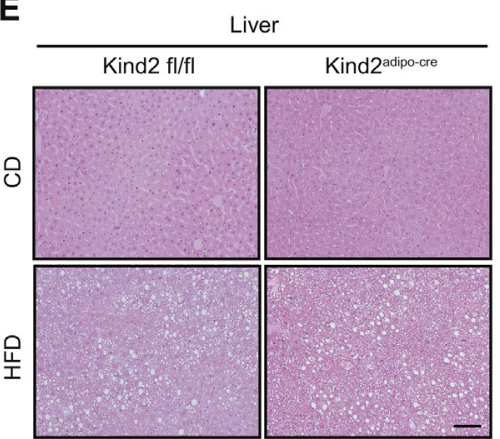

H

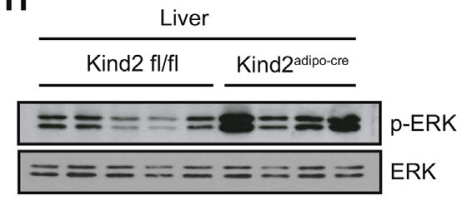

B

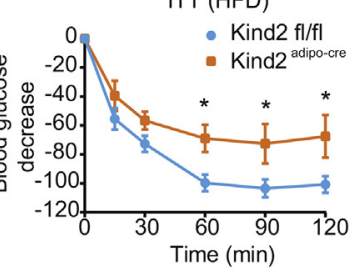

$\mathbf{F}$

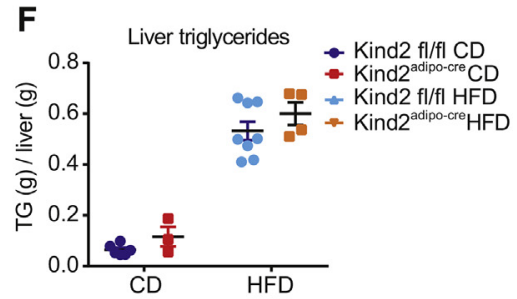

D

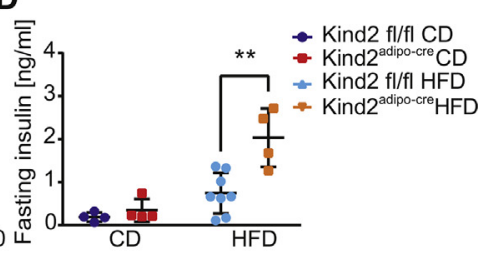

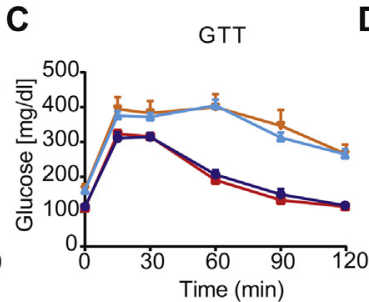

G

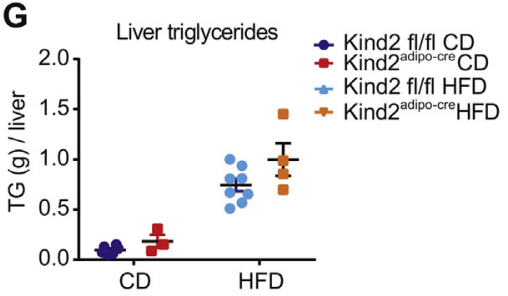

I

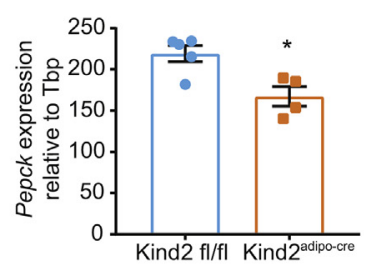

J

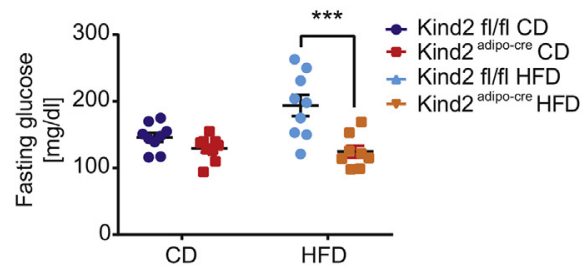

K

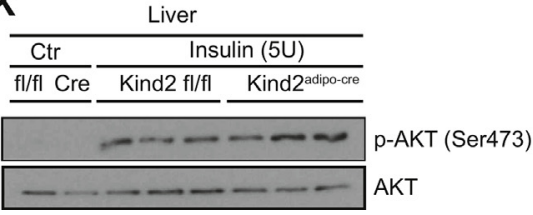

Figure 4: Loss of Kindlin-2 in adipose tissue causes systemic insulin resistance without hepatosteatosis and hepatic insulin resistance. (A) Plasma glucose concentration during intraperitoneal insulin tolerance test $(0.75 \mathrm{lU} / \mathrm{kg})$ in Kindlin-2 flox (Kind2 fl/fl) and Kindlin-2 flox; adiponectin-cre $\left(\right.$ Kind2 ${ }^{\text {adipo-cre }}$ ) mice fed chow diet $(\mathrm{CD})(\mathrm{n}=7) 14$ weeks $(\mathrm{n}=9-4)$. (B) Plasma glucose concentration during intraperitoneal insulin tolerance test $(1.25 \mathrm{lU} / \mathrm{kg})$ in Kind2 fl/fl and Kind2adipo-cre mice fed high-fat diet (HFD) for 14 weeks $(n=9-4)$. (C) Plasma glucose concentration during intraperitoneal glucose tolerance test $(2 \mathrm{~g} / \mathrm{kg})$ in Kind2 fl/fl and Kind2 ${ }^{\text {adipo-cre }}$ mice fed CD ( $\mathrm{n}=7$ ) and HFD for 14 weeks $(n=9-4)$. (D) Fasting insulin levels ( $\mathrm{ng} / \mathrm{ml})$ in Kind2 $\mathrm{fl} / \mathrm{fl}$ and Kind2 ${ }^{\text {adipo-cre }}$ mice fed $\mathrm{CD}(\mathrm{n}=4)$ and HFD for 14 weeks $(\mathrm{n}=8-4)$. (E) Representative H\&E staining of liver sections from Kind2 fl/fl and Kind2 ${ }^{\text {adipo-cre }}$ mice fed CD and HFD for 14 weeks (scale bar represents $\left.100 \mu \mathrm{m}\right)$. (F) Triglyceride content in liver (g/g) in Kind2 fl/fl and Kind2 ${ }^{\text {adipo-cre }}$ mice fed CD $(\mathrm{n}=4-3)$ and HFD for 14 weeks $(\mathrm{n}=8-4)$. (G) Total triglyceride content $(\mathrm{g})$ per whole liver in Kind2 fl/fl and Kind2 ${ }^{\text {adipo-cre }}$ mice fed CD $(\mathrm{n}=4-3)$ and HFD for 14 weeks $(\mathrm{n}=8-$ 4). (H) Representative western blot images for phospho-ERK and ERK in liver from Kindlin-2 fl/fl and Kind2 ${ }^{\text {adipo-cre }}$ mice fed HFD for 14 weeks ( $\left.\mathrm{n}=5-4\right)$. (I) Relative gene expression relative to Tbp of Pepck in liver from Kind2 fl/fl and Kind2 ${ }^{\text {adipo-cre }}$ mice fed HFD for 14 weeks $(\mathrm{n}=5-4)$. (J) Fasting glucose (mg/dl) in Kind2 fl/fl and Kind2 ${ }^{\text {adipo-cre }}$ mice fed CD $(n=9)$ and HFD for 14 weeks $(n=9-8)$. (K) Representative western blot images for phospho-AKT (Ser473) and AKT in liver from Kind2 fl/fl and Kind2adipo-cre mice fed CD for 13 weeks in the presence or absence (ctr $=$ control, saline) of insulin (in vivo insulin stimulation) $(\mathrm{n}=3)$. Data are shown as mean \pm SEM. Statistics were calculated using twoway ANOVA with Tukey's multiple comparison post-hoc test $\left({ }^{* *} p<0.001,{ }^{* *} p<0.01,{ }^{*} p<0.05\right)$.

integrin knockout mice (Figure 6A-B), suggesting that the increased vascular permeability is mediated through loss of $\beta 1$ integrin function in brown adipocytes.

Thus, if increased vascular permeability drives increased energy expenditure, a similar effect should be observed in $\beta 1$ integrin knockout mice. Indeed, Ucp1 mRNA (Fig. S6G) and protein levels (Figure 6F) on both $\mathrm{CD}$ and HFD were increased in $\beta 1$ integrin knockout mice, and lipid content in BAT was reduced (Figure 6G). Moreover, we observed increased energy expenditure upon acute cold exposure (Figure 6H) without changes in food intake (Fig. S6H) and RER (Fig. S6I), supporting that the increased BAT activity in Kind2 ${ }^{\text {adipo-cre }}$ mice is mediated by the regulation of $\beta 1$ integrin orchestrated transendothelial transport.

\section{DISCUSSION}

Maintaining or restoring adipose tissue function is pivotal to prevent the progression from obesity to insulin resistance and metabolic syndrome. Here, we show that expression although $\beta 1$ and $\beta 3$ integrins in adipose tissues is positively correlated with obesity in humans, albeit expression of $\beta 3$ integrin did not reach statistical significance in men. Integrins are also expressed in most stromal cells. Thus, potential changes in expression in these cells could contribute to the total tissue expression. Nevertheless, adipose-specific loss of $\beta 1$ integrin in mice results in a moderate reduction in fat mass without metabolic impairments. General loss of integrin activity through adipose-specific knockout of Kindlin-2, however, dramatically limits 

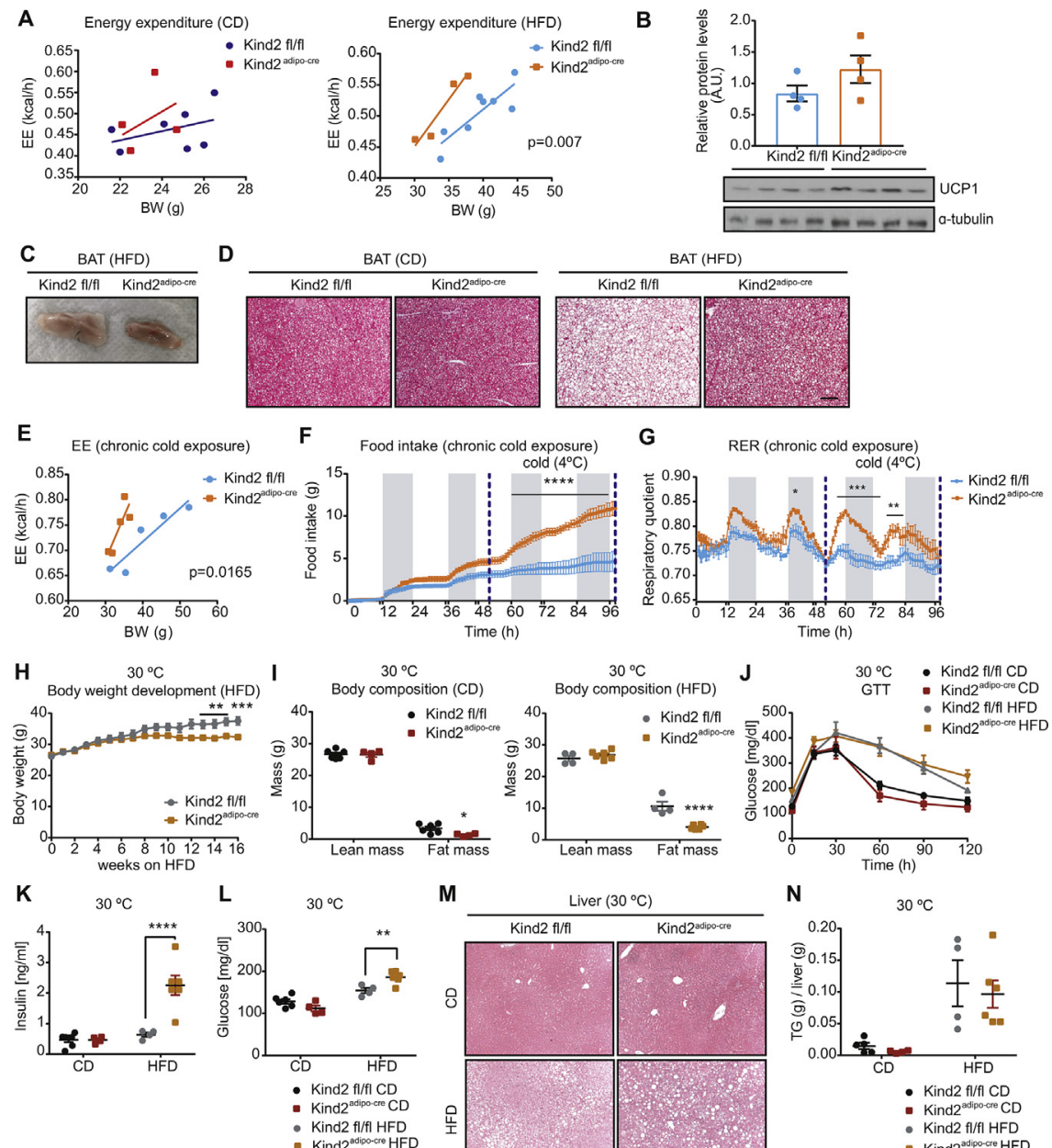

M Liver $\left(30^{\circ} \mathrm{C}\right)$
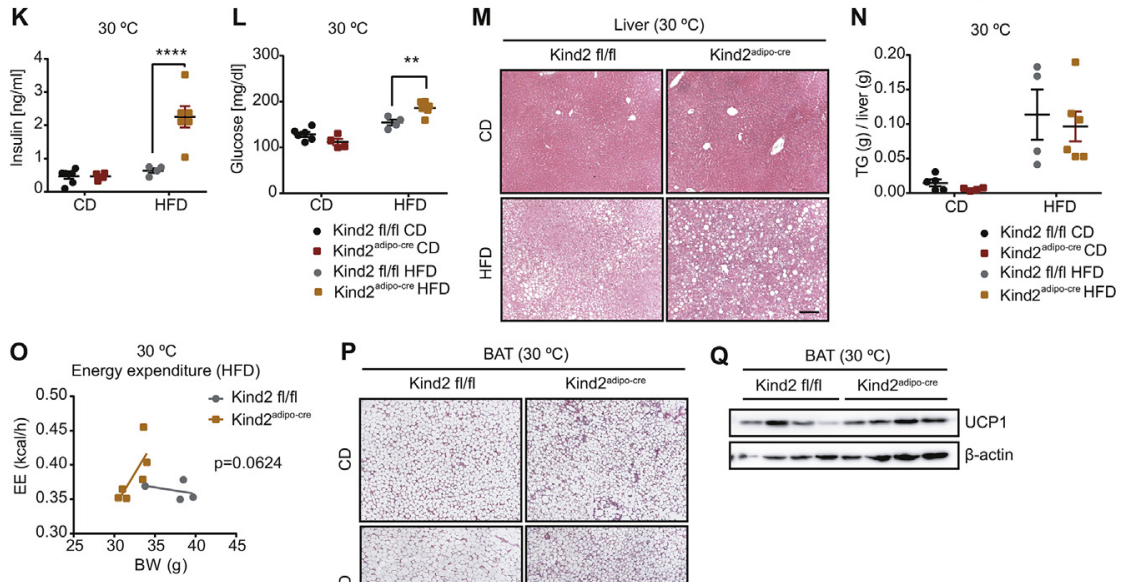

P

BAT $\left(30^{\circ} \mathrm{C}\right)$

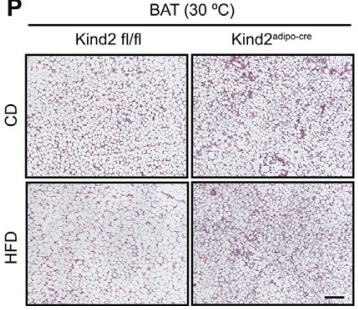

Q $\quad$ BAT $\left(30^{\circ} \mathrm{C}\right)$

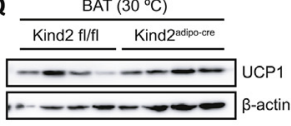

Figure 5: Loss of Kindlin-2 increases brown adipose tissue (BAT) activity independent from diet and housing temperature. (A) Body weight (g) correlated to total energy expenditure $(\mathrm{kcal} / \mathrm{h}$ ) in Kindlin-2 flox (Kind2 fl/fl) and Kindlin-2 flox; adiponectin-cre (Kind2adipo-cre) mice fed chow diet (CD) ( $\mathrm{n}=7-4)$ and high-fate diet (HFD) for 13 weeks $(n=8-4)$. (B) Representative western blot images for UCP1 and $\alpha$-tubulin in BAT from in Kind2 fl/fl and Kind2 ${ }^{\text {adipo-cre }}$ mice fed HFD for 14 weeks ( $\left.n=4\right)$. (C) Photograph of BAT from Kind2 fl/fl and Kind2 $2^{\text {adipo-cre }}$ mice fed HFD for 14 weeks. (D) Representative H\&E staining of BAT sections from in Kind2 fl/fl and Kind2 ${ }^{\text {adipo-cre }}$ mice fed CD and HFD for 14 weeks (scale bar represents $100 \mu \mathrm{m}$ ). (E) Body weight $(\mathrm{g})$ correlated to total energy expenditure $(\mathrm{kcal} / \mathrm{h})$ in Kind2 fl/fl and Kind2 ${ }^{\text {adipo-cre }}$ mice fed HFD for 14 weeks during chronic cold exposure at $4{ }^{\circ} \mathrm{C}$ for $48 \mathrm{~h}(\mathrm{n}=5-4)$. (F) Cumulative food intake $(\mathrm{g})$ for 4 days in in Kind2 fl/fl and Kind2 $2^{\text {adipo-cre }}$ mice fed HFD for 14 weeks. Blue lines represent chronic cold exposure at $4{ }^{\circ} \mathrm{C}$ for $48 \mathrm{~h}(\mathrm{n}=5-4)$. (G) RER in Kind2 fl/fl and Kind2 ${ }^{\text {adipo-cre }}$ mice fed HFD for 14 weeks during chronic cold exposure at $4{ }^{\circ} \mathrm{C}$ for $48 \mathrm{~h}$ ( $\left.\mathrm{n}=5-4\right)$. Blue lines represent chronic cold exposure at $4{ }^{\circ} \mathrm{C}$ for $48 \mathrm{~h}(\mathrm{n}=5-4)$. (H) Body weight development of in Kind2 fl/fl and Kind2 adipo-cre mice fed HFD for 16 weeks housed at thermoneutrality $\left(30^{\circ} \mathrm{C}\right)(\mathrm{n}=4-6)$. (I) Body composition represented as lean and fat mass weights $(\mathrm{g})$ of in Kind2 fl/fl and Kind2 ${ }^{\text {adipo-cre }}$ mice fed CD $(\mathrm{n}=6-4)$ and HFD ( $\left.\mathrm{n}=4-6\right)$ for 16 weeks housed at thermoneutrality $\left(30^{\circ} \mathrm{C}\right)$. ( $\left.\mathrm{J}\right)$ Plasma glucose concentration during intraperitoneal glucose tolerance test $(2 \mathrm{~g} / \mathrm{kg})$ in Kind2 fl/fl and Kind2 ${ }^{\text {adipo-cre }}$ mice fed $\mathrm{CD}(\mathrm{n}=6-4)$ and HFD $(\mathrm{n}=4-6)$ for 16 weeks housed at thermoneutrality $\left(30^{\circ} \mathrm{C}\right)$. (K) Fasting insulin levels $(\mathrm{ng} / \mathrm{ml})$ in mice Kind2 fl/fl and Kind2 ${ }^{\text {adipo-cre }}$ mice fed $\mathrm{CD}(\mathrm{n}=6-4)$ and $\mathrm{HFD}$ $(n=4-6)$ for 16 weeks housed at thermoneutrality $\left(30^{\circ} \mathrm{C}\right)$. (L) Fasting glucose levels $(\mathrm{mg} / \mathrm{dl})$ in mice Kind2 fl/fl and Kind2 ${ }^{\text {adipo-cre }}$ mice fed CD $(n=6-4)$ and $\mathrm{HFD}(\mathrm{n}=4-6)$ for 16 weeks housed at thermoneutrality $\left(30^{\circ} \mathrm{C}\right)$. (M) Representative H\&E staining of liver sections from Kind2 fl/fl and Kind2 $2^{\text {adipo-cre }}$ mice fed CD and HFD for 16 weeks housed at thermoneutrality $\left(30^{\circ} \mathrm{C}\right)($ scale bar represents $100 \mu \mathrm{m})$. (N) Triglyceride content in liver $(\mathrm{g} / \mathrm{g})$ in Kind2 fl/fl and Kind2 ${ }^{\text {adipo-cre }}$ mice fed CD $(\mathrm{n}=5-4)$ and HFD $(\mathrm{n}=4-6)$ for 16 weeks housed at thermoneutrality $\left(30^{\circ} \mathrm{C}\right)$. (0) Body weight $(\mathrm{g})$ correlated to total energy expenditure $(\mathrm{kcal} / \mathrm{h})$ in Kind2 fl/fl and Kind2 ${ }^{\text {adipo-cre }}$ mice fed $\mathrm{HFD}(\mathrm{n}=4-6)$ for 16 weeks housed at thermoneutrality $\left(30^{\circ} \mathrm{C}\right)$. (P) Representative H\&E staining of BAT sections from Kind2 fl/fl and Kind2 adipo-cre mice fed CD and HFD for 16 weeks housed at thermoneutrality $\left(30^{\circ} \mathrm{C}\right)$ (scale bar represents $\left.100 \mu \mathrm{m}\right)$. (Q) Representative western blot images for UCP1 and $\alpha$-tubulin in BAT from Kind2 fl/fl and Kind2 ${ }^{\text {adipo-cre }}$ mice fed HFD ( $\mathrm{n}=3-4$ ) for 16 weeks housed at thermoneutrality $\left(30^{\circ} \mathrm{C}\right)$. Data are shown as mean $\pm \mathrm{SEM}$. Statistics were calculated using two-way ANOVA with Tukey's multiple comparison post-hoc test $(* * * * p<0.0001, * * * p<0.001, * * p<0.01, * p<0.05)$. 
A
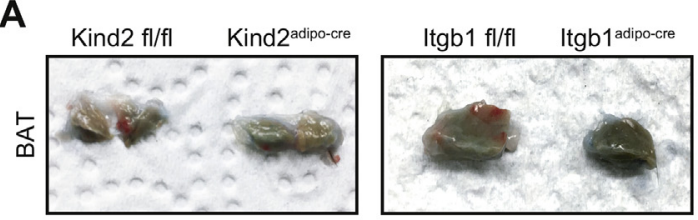

C

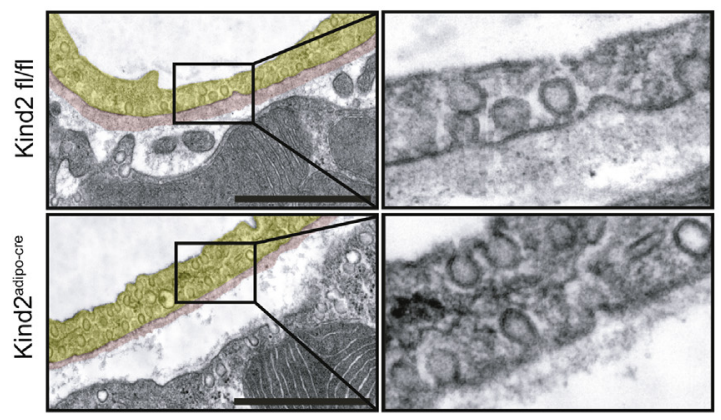

B

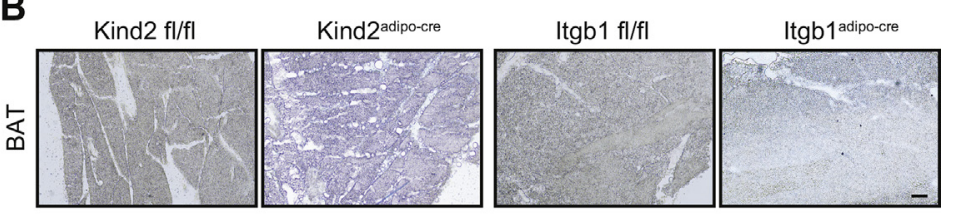

D

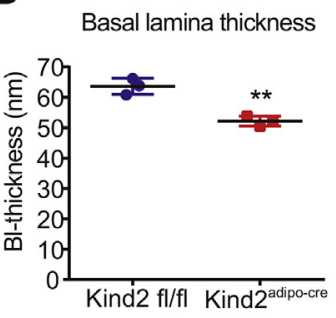

Basal lamina thickness

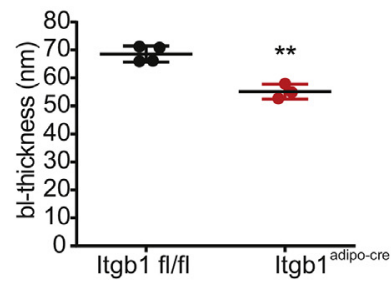

E

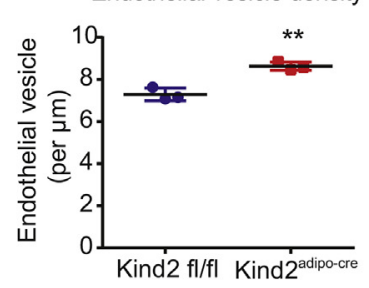

Endothelial vesicle density

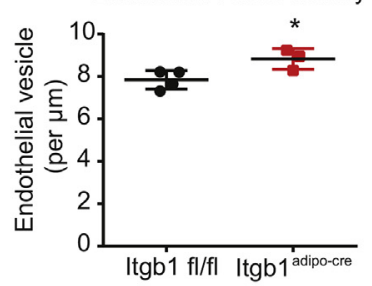

F

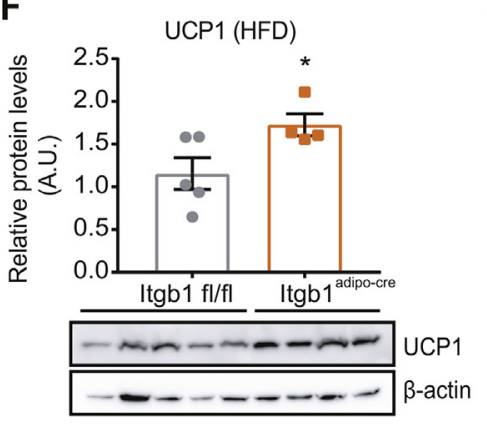

G

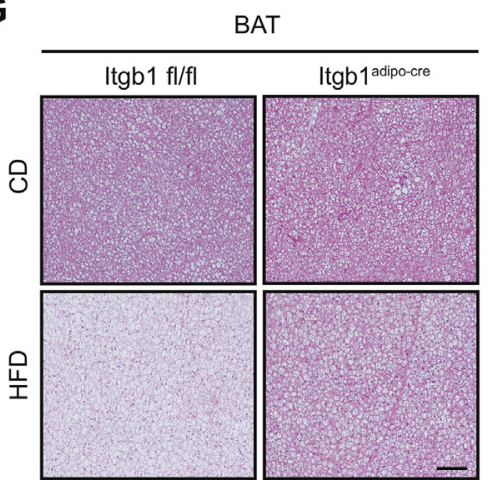

H Cold exposure period

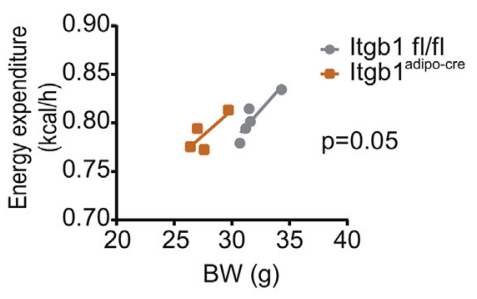

Figure 6: Loss of $\beta 1$ integrin activity in brown adipocytes increases vascular permeability in BAT. (A) Photograph of brown adipose tissue (BAT) from Kindlin-2 flox (Kind2 $\mathrm{fl} / \mathrm{fl})$ and Kindlin-2 flox; adiponectin-cre (Kind2 $2^{\text {adipo-cre }}$ ) mice fed chow diet (CD) for 8 weeks and integrin beta 1 flox mice (Itgb1 fl/fl) and Itgb1 flox; adiponectin-cre (Itgb1 ${ }^{\text {adipo-cre }}$ ) mice fed CD for 8 weeks after Evans blue (0.05\% in phosphate-buffered saline (PBS)) perfusion and fixation with paraformaldehyde (PFA, $4 \%$ ). (B) Representative images from BAT cryo-sections $(30 \mu \mathrm{m})$ after Evans blue perfusion and PFA fixation from Kind2 fl/fl and Kind2 ${ }^{\text {adipo-cre }}$ and Itgb1 fl/fl and Itgb $1^{\text {adipo-cre }}$ mice fed CD for 8 weeks (scale bar represents $100 \mu \mathrm{m})$. (C) Representative electron microscopy (EM) images showing adjacent parts of adipocytes in BAT from Kind2 fl/fl and Kind2 ${ }^{\text {adipo-cre }}$ and Itgb1 fl/fl and Itgb1 ${ }^{\text {adipo-cre }}$ mice fed CD for 8 weeks (scale bar represents $1 \mu \mathrm{m}$ ). (D) Basal lamina thickness quantification $(\mu \mathrm{m})$ measured by EM at 15 different points per vessel. Mean value is calculated per vessel and mouse in BAT from Kind2 fl/fl and Kind2 ${ }^{\text {adipo-cre }}$ and Itgb1 fl/fl and Itgb $1^{\text {adipo-cre }}$ mice fed CD for 8 weeks $(n=4-3)$. (E) Endothelial vesicle density (per $\left.\mu \mathrm{m}\right)$ measured by EM in BAT from Kind2 fl/fl and Kind2 $2^{\text {adipo-cre }}$ and Itgb1 fl/fl and Itgb1 ${ }^{\text {adipo-cre }}$ mice fed $C D$ for 8 weeks $(n=3)$. (F) Representative western blot images for UCP1 and $\alpha$-tubulin in BAT from Itgb1 fl/fl and Itgb1 ${ }^{\text {adipo-cre }}$ mice fed high-fat diet (HFD) for 14 weeks $(n=5-4)$. (G) Representative H\&E staining of BAT sections from Itgb1 fl/fl and Itgb1 ${ }^{\text {adipo-cre }}$ mice fed $\mathrm{CD}$ and HFD for 14 weeks (scale bar represents $100 \mu \mathrm{m})$. (H) Body weight $(\mathrm{g})$ correlated to energy expenditure $(\mathrm{kcal} / \mathrm{h})$ in Itgb1 fl/fl and Itgb $1^{\text {adipo-cre }}$ mice fed HFD for 14 weeks during acute cold exposure at $4{ }^{\circ} \mathrm{C}$ for $5 \mathrm{~h}(\mathrm{n}=5-4)$. Data are shown as mean \pm SEM. Statistics were calculated using two-way ANOVA with Tukey's multiple comparison posthoc test $(* * p<0.01, * p<0.05)$.

adipose tissue expansion, triggering fibrosis, inflammation, and apoptosis in white, but not brown, fat. This is very similar to the adipose tissue-specific knockout of the insulin receptor [36,37]. Indeed, we find that Kindlin-2 deficient adipocytes, prior to the development of inflammation, are insulin-resistant. Previous work by Michael Czech and Erkki Ruoslahti suggested an interaction of $\beta 1$ and $\beta 3$ integrins with insulin action $[28,29]$. Here, we confirm that integrin signaling regulates insulin signaling in adipocytes in vivo. However, $\beta 1$ integrins 
also interact with the IGF1R [31] and adipocytes express IR/IGF1R hybrid receptors [44]. Thus, we cannot exclude that the IGF1R contributes to the observed changes in insulin action. Additional studies using IGF1R and IR single and double knockout adipocyte are needed to address this point.

Nevertheless, insulin and integrin signaling show overlapping intracellular signaling pathways, of which several can contribute to the observed adipose dysfunction [28]. Thus, reduced Erk and Akt signaling upon loss of integrin action could impair insulin action. Among the various effectors, we find a reduction in mTORC1 activity in white, but not brown, adipocytes, which appears as the primary mediator of the observed loss in WAT mass, inflammation, and fibrosis as adipose selective raptor knockout has an almost identical phenotype in white adipose tissue [38,45]. mTORC1 integrates multiple upstream signals, including integrin and insulin receptor signaling [46,47]. However, loss of integrin activity was observed in both white and brown fat, but insulin resistance was restricted to WAT, as was the reduction in mTORC1 activity. Thus, the impaired mTORC1 activity observed in Kindlin-2 knockout mice appears to be due to impaired insulin rather than integrin signaling, further substantiating the significant role of integrins in the modulation of insulin action in white adipocytes. Importantly, the absence of adipocyte insulin resistance in $\beta 1$ integrin-deficient adipocytes suggests that $\beta 3$ containing integrins can, at least, compensate for the loss of $\beta 1$ integrins, essentially limiting the ECM components mediating these effects to RGD containing fibronectin and vitronectin $[48,49]$.

This raises the interesting possibility that changes in the composition of the ECM, such as during tissue expansion and inflammation, can directly and selectively impact on adipocyte insulin sensitivity. This is in line with a recent study showing that obesity-induced insulin resistance in mice can precede macrophage accumulation and inflammation in adipose tissue [50]. Thus, integrin activity in mature white adipocytes appears to predominantly affect insulin action, which in some ways, is in contradiction to the conclusions drawn in a recent report on adipose-selective knockout of Kindlin-2 [24]. It is difficult to conclude whether the observed tissue fibrosis and apoptosis upon loss of Kindlin-2 are due to impaired integrin or insulin action, as both can mediate these processes. However, a dependency on insulin receptor action is more likely, as primary white adipocytes from young CD-fed Kindlin-2 knockouts did not show increased expression of proinflammatory cytokines, suggesting an indirect effect. Furthermore, the differentiation of brown and white preadipocytes did not show strongly impaired adipogenesis or signs of anoikis, most likely due to the relatively late deletion of Kindlin-2 through cre expression under the control of the adiponectin promoter.

In contrast to WAT, loss of Kindlin-2/integrin activity in BAT has limited effects on insulin sensitivity and mTORC1 activation. It will be interesting to determine if potential differences in the ECM between WAT and BAT could explain the minor role of integrins in regulating brown adipocyte insulin sensitivity or other signals compensate for the loss of integrins in the future. However, the fact that insulin/mTORC1 action is preserved in Kindlin-2 knockout mice helps to explain the systemic differences between adipose selective knockout of Kindlin-2 and raptor. Loss of raptor in adipocytes results in lipodystrophy and, if deleted using adiponectin-cre, insulin resistance, hepatosteatosis, and glucose intolerance. Loss of Kindlin-2 also results in systemic insulin resistance. However, we did not observe hepatosteatosis. In fact, the liver of Kind $2^{\text {adipo-cre }}$ mice appeared protected from HFD-induced steatosis and insulin resistance, suggesting that the energy that is not stored in white fat is either not taken in or expended. Fecal caloric content was increased in HFD-fed Kind2 $2^{\text {adipo-cre }}$ mice. However, the same was observed in conditional raptor knockout mice, which showed strong hepatosteatosis [38]. Indirect calorimetry did not indicate differences in food intake or activity, but increased energy expenditure, especially when mice were fed an HFD. However, energy expenditure of Kind $2^{\text {adipo-cre }}$ mice, as well as UCP-1 protein levels in BAT were increased not only at RT and $4{ }^{\circ} \mathrm{C}$, but also at thermoneutrality when combined with HFD feeding, a situation of low sympathetic activity, usually associated with inactivation of brown fat [42]. This suggests that sympathetic signals are not the primary mediators of the increased BAT activity in adipose Kindlin-2 and $\beta 1$ integrin knockouts. In addition to the dense innervation of BAT, every brown adipocyte is also in contact with blood vessels, only separated by a basement membrane [43]. Fasting alters the endothelial basement membrane structure in BAT, resulting in increased transport into the intercellular space [51] as well as increased glucose uptake into BAT of humans [52]. This suggests that changes in the endothelial basement membrane in BAT can increase substrate delivery to brown adipocytes and thereby its activity. Integrins are important organizers of the basement membrane [53], and we found a reduction in the thickness of the endothelial basement membrane in Kind2 $2^{\text {adipo-cre }}$ and Itgb1 $1^{\text {adipo- }}$ cre mice. We also found increased penetration of perfused Evans blue into BAT. However, this did not result in impaired endothelial cell-cell contacts, but rather increased endothelial vesicles, indicative of increased trans-endothelial transport. Therefore, we conclude that loss of integrin activation in brown adipocytes results in an impaired basement membrane between brown adipocytes and endothelial cells causing increased trans-endothelial transport and more substrate delivery to brown adipocytes, thereby uncoupling brown adipocyte activity from sympathetic inputs. The absence of such a phenotype in adipose-selective FAK knockouts [27] suggests that this is mediated through the role of integrins in organizing the ECM rather than transmitting signals intracellularly. Nevertheless, we cannot exclude that changes in the ECM composition could directly affect signaling in brown adipocytes, contributing to the observed phenotype. Moreover, a detailed assessment of nutrient (glucose, FFA, etc.) uptake into brown adipocytes would be needed to solidify our conclusions of increased substrate delivery into brown adipocytes. Increased substrate delivery to BAT could also explain the larger effect on energy expenditure upon HFD feeding of Kind-2 $2^{\text {adipo-cre }}$ mice as, due to the inability of WAT to store excessive calories, more substrate is in the circulation. Furthermore, the hyperactivation of BAT also helps to explain the relative improvement in hepatic insulin sensitivity and the absence of ectopic lipid accumulation in skeletal muscle and liver in context of loss of WAT mass. This appears to cause atypical lipodystrophy without increased blood triglycerides, no non-alcoholic fatty liver disease (NAFLD), and increased hepatic insulin sensitivity. Interestingly, in contrast to WAT insulin sensitivity, the effect on endothelial transport seems to be largely dependent on $\beta 1$ integrins, as loss of $\beta 1$ integrin phenocopies the BAT phenotype of Kind2 ${ }^{\text {adipo-cre }}$ mice.

Thus, our data establish integrin activity in adipose tissue as an important regulator of systemic metabolism, with a critical function in regulating WAT insulin sensitivity. The important metabolic role of BAT and the differential effects of loss of integrin function, as well as insulin action in brown versus white fat, result in a complex metabolic phenotype. Loss of integrin activity in WAT causes an age-acquired atypical lipodystrophy, associated with systemic insulin resistance, without impairing the liver due to a second function of integrins in BAT to regulate trans-endothelial substrate delivery by modulating basement membrane thickness.

We observed a correlation of $\beta 1$ and $\beta 3$ integrin expression with obesity and metrics of insulin resistance in humans, suggesting a 
potentially conserved function between humans and mice. Large parts of human BAT are in an inactive state. However, as loss of $\beta 1$ integrin activity in brown adipocytes uncouples BAT activity from sympathetic activity, it is tempting to speculate that, similar to mice, impaired adipose integrin activity in humans also results in an atypical lipodystrophy with loss of WAT mass in the absence of ectopic lipid accumulation due to hyperactivation of BAT. WAT fibrosis and inflammation are hallmarks of adipose dysfunction and linked to insulin resistance and type 2 diabetes [4]. However, our data suggest that changes in the composition and structure of the ECM surrounding white adipocytes can directly and profoundly change insulin sensitivity and directly contribute to the predisposition of patients to the development of metabolic complications [54].

In summary, our study reveals novel concepts for the regulation of white adipocyte insulin action and tissue expansion as well as brown fat activity by previously unrecognized distinct functions of active integrins in white and brown adipocytes.

\section{AUTHOR CONTRIBUTIONS}

FJR0, JW, and SU designed and conducted the experiments. FJRO and SU wrote the manuscript. MK conducted the electron microcopy experiments. SR conducted the PLA assay. TB, SZ, YO, and TG performed experiments. AF conducted size distribution analysis of adipocytes. CGC, TJS, TM, RF, and MM designed experiments. MB provided the human data analysis.

\section{ACKNOWLEDGMENTS}

This work was supported by the project Aging and Metabolic Programming (AMPro). FJRO was supported by a grant to postdoctoral researchers at foreign Universities and Research Centers from the "Alfonso Martín Escudero Foundation", Spain. J. W. received support from the Chinese Scholarship Council. Y.0. received support through the Alexander von Humboldt-Stiftung. TDM was supported by the German Research Foundation (DFG) grants TRR152 and TRR296. C.G.C was supported by the European Research Council ERC (StG AstroNeuroCrosstalk no. 757393).

\section{CONFLICT OF INTEREST}

The authors declare no competing interests.

\section{APPENDIX A. SUPPLEMENTARY DATA}

Supplementary data to this article can be found online at https://doi.org/10.1016/j. molmet.2020.101147.

\section{REFERENCES}

[1] Luo, L., Liu, M., 2016. Adipose tissue in control of metabolism. Journal of Endocrinology 231(3):R77-R99.

[2] Schoettl, T., Fischer, I.P., Ussar, S., 2018. Heterogeneity of adipose tissue in development and metabolic function. Journal of Experimental Biology 221(Pt Suppl 1).

[3] Sun, K., Kusminski, C.M., Scherer, P.E., 2011. Adipose tissue remodeling and obesity. Journal of Clinical Investigation 121(6):2094-2101.

[4] Sun, K., Tordjman, J., Clement, K., Scherer, P.E., 2013. Fibrosis and adipose tissue dysfunction. Cell Metabolism 18(4):470-477.
[5] Boucher, J.K.A., Kahn, C.R., 2014. Insulin receptor signaling in normal and insulin-resistant states. Cold Spring Harbor Perspectives Biology 6(1).

[6] Virtue S, V.-P.A., 2010. Adipose tissue expandability, lipotoxicity and the Metabolic Syndrome-an allostatic perspective. Biochimica et Biophysica Acta 1801(3):338-349.

[7] Lin, Chun, T.H., Kang, L., 2016. Adipose extracellular matrix remodelling in obesity and insulin resistance. Biochemical Pharmacology 119:8-16.

[8] Graja, A.G.-C.F., Jank, A.M., Gohlke, S., Ambrosi, T.H., Jonas, W., Ussar, S., et al., 2018. Loss of periostin occurs in aging adipose tissue of mice and its genetic ablation impairs adipose tissue lipid metabolism. Aging Cell 17(5):e12810.

[9] Kechagia JZ, I.J., Roca-Cusachs, P., 2019. Integrins as biomechanical sensors of the microenvironment. Nature Reviews Molecular Cell Biology 20(8):457473.

[10] Williams, A.S., Kang, L., Wasserman, D.H., 2015. The extracellular matrix and insulin resistance. Trends in Endocrinology and Metabolism 26(7):357-366.

[11] Chloé, C., Féral, J.G.N., Kummer, Christiane, Slepak, Marina, Olefsky, Jerrold M., Ginsberg, Mark H., 2008. Blockade of alpha4 integrin signaling ameliorates the metabolic consequences of high-fat diet-induced obesity. Diabetes 57(7):1842-1851.

[12] Kang, L., A, J., Lee-Young, R.S., Zhang, Z., James, F.D., Neufer, P.D., et al., 2011. Diet-induced muscle insulin resistance is associated with extracellular matrix remodeling and interaction with integrin alpha2beta1 in mice. Diabetes 60(2):416-426.

[13] Yoshikazu Takada, X.Y., Scott, Simon, 2007. The integrins. Genome Biology $8(5): 215$.

[14] Calderwood, D.A.C., I, D., Critchley, D.R., 2013. Talins and kindlins: partners in integrin-mediated adhesion. Nature Reviews Molecular Cell Biology 14(8): $503-517$.

[15] Theodosiou, M.W.M., Böttcher, R.T., Rognoni, E., Veelders, M., Bharadwaj, M., Lambacher, A., et al., 2016. Kindlin-2 cooperates with talin to activate integrins and induces cell spreading by directly binding paxillin. Elife 5 : e10130.

[16] Ussar, S., Wang, H.V., Linder, S., Fassler, R., Moser, M., 2006. The Kindlins: subcellular localization and expression during murine development. Experimental Cell Research 312(16):3142-3151.

[17] Harburger, D.S., Bouaouina, M., Calderwood, D.A., 2009. Kindlin-1 and -2 directly bind the C-terminal region of beta integrin cytoplasmic tails and exert integrin-specific activation effects. Journal of Biological Chemistry 284(17): 11485-11497.

[18] Kloeker, S., Major, M.B., Calderwood, D.A., Ginsberg, M.H., Jones, D.A., Beckerle, M.C., 2004. The Kindler syndrome protein is regulated by transforming growth factor-beta and involved in integrin-mediated adhesion. Journal of Biological Chemistry 279(8):6824-6833.

[19] Ma, Y.Q., Qin, J., Wu, C., Plow, E.F., 2008. Kindlin-2 (Mig-2): a co-activator of beta3 integrins. The Journal of Cell Biology 181(3):439-446.

[20] Montanez, E., Ussar, S., Schifferer, M., Bosl, M., Zent, R., Moser, M., et al., 2008. Kindlin-2 controls bidirectional signaling of integrins. Genes \& Development 22(10):1325-1330.

[21] Shi, X., Ma, Y.Q., Tu, Y., Chen, K., Wu, S., Fukuda, K., et al., 2007. The MIG-2/ integrin interaction strengthens cell-matrix adhesion and modulates cell motility. Journal of Biological Chemistry 282(28):20455-20466.

[22] Bouvard, D.B.C., Gustafsson, E., Aszódi, A., Bengtsson, T., Berna, A., Fässler, R., 2001. Functional consequences of integrin gene mutations in mice. Circulation Research 89(3):211-223.

[23] Bledzka, K., Liu, J., Xu, Z., Perera, H.D., Yadav, S.P., Bialkowska, K., et al., 2012. Spatial coordination of kindlin-2 with talin head domain in interaction with integrin beta cytoplasmic tails. Journal of Biological Chemistry 287(29): 24585-24594. 
[24] Gao, H., Guo, Y., Yan, Q., Yang, W., Li, R., Lin, S., et al., 2019. Lipoatrophy and metabolic disturbance in mice with adipose-specific deletion of kindlin-2. JCI Insight 4(13).

[25] Hynes, R., 2002. Integrins: bidirectional, allosteric signaling machines. Cell 110(6):673-687.

[26] Ilić, D.F.Y., Kanazawa, S., Takeda, N., Sobue, K., Nakatsuji, N., Nomura, S., et al., 1995. Reduced cell motility and enhanced focal adhesion contact formation in cells from FAK-deficient mice. Nature 377(6549):539-544.

[27] Luk, C.T., Shi, S.Y., Cai, E.P., Sivasubramaniyam, T., Krishnamurthy, M., Brunt, J.J., et al., 2017. FAK signalling controls insulin sensitivity through regulation of adipocyte survival. Nature Communications 8:14360.

[28] Guilherme, A.T.K., Czech, M.P., 1998. Cross-talk between insulin receptor and integrin alpha5 beta1 signaling pathways. Journal of Biological Chemistry 273(36).

[29] Vuori, K.R.E., 1994. Association of insulin receptor substrate-1 with integrins. Science 266(190):1576-1578.

[30] Schneller, M.V.K., Ruoslahti, E., 1997. Alphavbeta3 integrin associates with activated insulin and PDGFbeta receptors and potentiates the biological activity of PDGF. The EMBO Journal 16(18):5600-5607.

[31] Wang, H.V., Chang, L.W., Brixius, K., Wickstrom, S.A., Montanez, E., Thievessen, I., et al., 2008. Integrin-linked kinase stabilizes myotendinous junctions and protects muscle from stress-induced damage. The Journal of Cell Biology 180(5):1037-1049.

[32] Potocnik, A.J., C, B., Fässler, R., 2000. Fetal and adult hematopoietic stem cells require beta1 integrin function for colonizing fetal liver, spleen, and bone marrow. Immunity 12(6):653-663.

[33] Lillie, R.D., P, P., Donaldson, P.T., 1976. Hematoxylin substitutes: a survey of mordant dyes tested and consideration of the relation of their structure to performance as nuclear stains. Stain Technology 51(1):25-41.

[34] Pfaffl, M., 2001. A new mathematical model for relative quantification in realtime RT-PCR. Nucleic Acids Research 29(9).

[35] Heemskerk, J.W., Mattheij, N.J., Cosemans, J.M., 2013. Platelet-based coagulation: different populations, different functions. Journal of Thrombosis and Haemostasis 11(1):2-16.

[36] Qiang, G.W.K.H., Xu, S., Pham, H.A., Parlee, S.D., Burr, A.A., Gil, V., et al., 2016. Lipodystrophy and severe metabolic dysfunction in mice with adipose tissue-specific insulin receptor ablation. Molecular Metabolism 5(7):480-490.

[37] Boucher, J., Softic, S., El Ouaamari, A., Krumpoch, M.T., Kleinridders, A., Kulkarni, R.N., et al., 2016. Differential roles of insulin and IGF-1 receptors in adipose tissue development and function. Diabetes 65(8):2201-2213.

[38] Lee, P.L., Tang, Y., Li, H., Guertin, D.A., 2016. Raptor/mTORC1 loss in adipocytes causes progressive lipodystrophy and fatty liver disease. Molecular Metabolism 5(6):422-432.

[39] Wu, J., Bostrom, P., Sparks, L.M., Ye, L., Choi, J.H., Giang, A.H., et al., 2012. Beige adipocytes are a distinct type of thermogenic fat cell in mouse and human. Cell 150(2):366-376.
[40] Cannon, B., N, J., 2004. Brown adipose tissue: function and physiological significance. Physiological Reviews 84(1):277-359.

[41] Clayton ZS, M.C., 2018. Short-term thermoneutral housing alters glucose metabolism and markers of adipose tissue browning in response to a high-fat diet in lean mice. American Journal of Physiology - Regulatory, Integrative and Comparative Physiology 315(4):R627-R637.

[42] Cui, X.,N.N., Zarebidaki, E., Cao, Q., Li, F., Zha, L., Bartness, T., et al., 2016. Thermoneutrality decreases thermogenic program and promotes adiposity in high-fat diet-fed mice. Physiological Reports 4(10).

[43] Peirce, V., P, V., Vidal-Puig, A., 2016. Adipose structure (white, Brown, beige). Metabolic syndrome. p. 369-96.

[44] Boucher, J., Tseng, Y.H., Kahn, C.R., 2010. Insulin and insulin-like growth factor-1 receptors act as ligand-specific amplitude modulators of a common pathway regulating gene transcription. Journal of Biological Chemistry 285(22): 17235-17245.

[45] Polak, P., Cybulski, N., Feige, J.N., Auwerx, J., Ruegg, M.A., Hall, M.N., 2008. Adipose-specific knockout of raptor results in lean mice with enhanced mitochondrial respiration. Cell Metabolism 8(5):399-410.

[46] Dibble, C.C., Manning, B.D., 2013. Signal integration by mTORC1 coordinates nutrient input with biosynthetic output. Nature Cell Biology 15(6):555-564.

[47] Bui, T., Rennhack, J., Mok, S., Ling, C., Perez, M., Roccamo, J., et al., 2019. Functional redundancy between beta1 and beta3 integrin in activating the IR/ Akt/mTORC1 signaling Axis to promote ErbB2-driven breast cancer. Cell Reports 29(3):589-602 e586.

[48] Horton, M., 1997. The $\alpha v \beta 3$ integrin "vitronectin receptor". The International Journal of Biochemistry \& Cell Biology 29(5).

[49] Charo IF, N.L., Smith, J.W., Cheresh, D.A., 1990. The vitronectin receptor alpha $v$ beta 3 binds fibronectin and acts in concert with alpha 5 beta 1 in promoting cellular attachment and spreading on fibronectin. The Journal of Cell Biology 111.

[50] Shimobayashi, M., Albert, V., Woelnerhanssen, B., Frei, I.C. Weissenberger, D., Meyer-Gerspach, A.C., et al., 2018. Insulin resistance causes inflammation in adipose tissue. Journal of Clinical Investigation 128(4): $1538-1550$.

[51] Yudasaka, M., Yomogida, Y., Zhang, M., Nakahara, M., Kobayashi, N., Tanaka, T., et al., 2018. Fasting-dependent vascular permeability enhancement in Brown adipose tissues evidenced by using carbon nanotubes as fluorescent probes. Scientific Reports 8(1):14446.

[52] Vrieze, A.S.J., Admiraal, W.M., Soeters, M.R., Nieuwdorp, M., Verberne, H.J., Holleman, F., 2012. Fasting and postprandial activity of brown adipose tissue in healthy men. Journal of Nuclear Medicine 53(9):1407-1410.

[53] 0jakian GK, S.R., 1994. Regulation of epithelial cell surface polarity reversal by $\beta 1$ integrins. Journal of Cell Science 107.

[54] Kahn, C.R., W, G., Lee, K.Y., 2019. Altered adipose tissue and adipocyte function in the pathogenesis of metabolic syndrome. Journal of Clinical Investigation 129(10):3990-4000. 